\title{
A FISIOGNOMÍA EN LA CARTILLA DEL PINTOR VALENCIANO VICENTE SALVADOR GÓMEZ ${ }^{1}$
}

\author{
MARÍA DEL MAR ALBERO MUÑOZ \\ Universidad de Murcia \\ mmalbero@um.es
}

\begin{abstract}
Resumen: Avanzado el siglo XVII algunos artistas redactaron los primeros tratados artísticos en España, pero también decidieron componer sus propias cartillas de dibujo. Es el caso del artista valenciano Vicente Salvador Gómez quien en 1674 comenzó uno de los primeros ejemplos que se conserva, la Cartilla y fundamentales reglas de la pintura. Director de la Academia de Pintura del convento de Santo Domingo, coetáneo de Ribera y de Alonso Cano, poseyó una de las más valiosas bibliotecas de artista conocida, con una envidiable colección de cuatrocientos volúmenes. Este trabajo estudia las páginas que se conservan de su cartilla y muestra cómo el artista conocía las teorías artísticas que circulaban por Europa, entre ellas las fisiognómicas. Esta materia, entre la mántica y la ciencia fue objeto de estudio de numerosos artistas y había sido incluida en los tratados de Leonardo o Durero, pero también en España por Carducho. Los restos de la cartilla que han llegado hasta nosotros muestran este conocimiento del valenciano por las teorías fisiognómicas de raíz clásica, pero sus dibujos también suponen los primeros y únicos ejemplos de ilustración de estas teorías en España en el siglo XVII, uniendo la imagen y la palabra en un ejercicio de marcada vocación didáctica.
\end{abstract}

Palabras Clave: Cartillas de dibujo / fisiognomía / tratados / siglo XVII.

Abstract: During the 17th century some artists wrote the first artistic treaties in Spain, and decided to compose their own drawing books too. It is the case of the Valencian artist Vicente Salvador Gómez who in 1674 began one of the first examples that is preserved, the Cartilla y fundamentales reglas de la pintura. Director of the Academy of Painting of the convent of Santo Domingo, contemporary of Ribera and Alonso Cano, owned one of the most valuable and know artist's library, with an enviable collection of four hundred volumes. This paper studies the pages that are conserved of the drawing books and shows how the artist knew the artistic theories that circulated by Europe, among them physiognomics. This subject, between the mantic and the science was object of study of numerous artists and had been included in the treaties of Leonardo or Dürer, but also in Spain by Carducho. The remains of the drawing book shows the knowledge of the painter on the clasic physiognomic theories, but their drawings also suppose the first and only examples of illustration of these theories in Spain in XVII century, uniting the image and the word in an exercise of marked didactic vocation.

Key words: Drawing book / physiognomy / treatises / XVIIth century.

\section{Introducción. Las cartillas de dibujo en España en el siglo XVII}

Al igual que había sucedido con la redacción de los tratados artísticos, algunos pintores españoles del siglo XVII siguieron el precedente europeo y decidieron componer sus propias cartillas de dibujo con un marcado carácter didáctico. Del mismo modo que los Carracci habían preparado la Scuola perfetta per imparare a disegnare tutto il corpo humano para su academia "degli Incamminati" (Roma, 1599); Odoardo Fialleti Il vero modo et or-

\footnotetext{
* Fecha de recepción: 15 de abril de 2017 / Fecha de aceptación: 3 de septiembre de 2017.

1 Este artículo se realizó gracias a una Beca José de Castillejo del MEC en el Instituto Warburg de la Universidad de Londres. Desde aquí deseo expresar mi agradecimiento al Dr. Hope por su hospitalidad y al Dr. Taylor por su invitación a presentar los
} 
dine per dissegnar le parti et membra del corpo humano (Venecia, 1608) y De excelentis y nobilitate delineatoris libri duo (Venecia, 1611) y Guercino el Livre de portraiture (París, 1642) los españoles Pedro de Villafranca y Malagón con su Cartilla para aprender a dibujar (circa 1637); Vicente Salvador Gómez con la Cartilla y fundamentales reglas de la pintura (1674) y José García Hidalgo con los Principios para estudiar el nobilísimo arte de la pintura (1693) elaboraron las primeras cartillas de dibujo conocidas en el siglo XVII español. ${ }^{2}$

Estas cartillas se plantearon con una vocación de función práctica para la enseñanza del dibujo tanto en talleres como en academias. ${ }^{3}$ Su utilidad se basaba en facilitar la tarea tanto del maestro como del aprendiz en el proceso de adiestramiento de la técnica del dibujo, considerada desde siempre una habilidad básica y esencial para alcanzar la perfección en cualquiera de las tres artes, la arquitectura, la escultura o la pintura, mediante la copia repetitiva de imágenes. ${ }^{4}$ El propósito de estas cartillas era ofrecer los mismos principios que se recogían de forma teórica en los tratados, es decir, la simetría, la proporción, la perspectiva, la anatomía, la geometría y la fisiognomía, pero formulando sus principios de una forma eminentemente práctica, basándose para ello en la continua repetición de modelos hasta que se alcanzase su pleno dominio. El uso de estos cuadernos se acompañaba y completaba en los talleres con la copia de dibujos sueltos, de estampas y de grabados, así como de modelos en escultura, maniquíes y en ocasiones por la consulta de los tratados, obras ya mucho más difíciles de entender y que requerían una mayor formación de los jóvenes aprendices. $^{5}$

Siguiendo la tradición italiana, autores como Carducho, Palomino o Pacheco, describían la práctica común de comenzar la enseñanza del dibujo por los rasgos del rostro. Esta técnica, desarrollada ya en el programa pedagógico de Federico Zuccaro en la Academia de San Lucas, ${ }^{6}$ recomendaba específicamente comenzar con el dibujo de los ojos, a continuación con las narices, bocas y orejas y una vez que se dominaba perfectamente su ejecución, se procedía al aprendizaje del conjunto de rasgos del rostro y posteriormente cabezas completas, manos, brazos, pies, piernas, troncos quedando por último la composición del cuerpo humano completo en distintas actitudes. Para todo ello se seguía un orden en virtud del cual un alumno no pasaba a dibujar una parte del cuerpo sin haber conseguido el pleno dominio del dibujo de la parte anterior.?

Una vez completada la formación de aprendiz y alcanzado el nivel de oficial, los artistas debían dominar la representación de la figura humana bajo todos sus principios. Es decir, desde el punto de vista anatómico, de la proporción y simetría entre las distintas partes y con respecto al resto del cuerpo y de la expresión que le correspondía, y todo ello además, en todo tipo de actitudes, poses y movimientos, no solo físicos sino también anímicos. La excelencia a la que debían aspirar les exigía la capacidad en la representación de imágenes de gran corrección física, pero también que fueran capaces de expresar sentimientos o de

primeros resultados de esta investigación en la conferencia Physiognomy in the drawing book of Vicente Salvador Gómez que impartí en el Seminario de Historia del Arte del Instituto Warburg. Estoy especialmente en deuda con la Dra. Montagu por leer la primera versión y por sus importantes sugerencias que, sin duda, han enriquecido este texto. Este trabajo se inscribe en el proyecto de investigación Decoro, Imagen y Apariencia: Tecnologías y espacios en torno al cuerpo en los programas políticos y religiosos de los siglos XVII al XIX en España financiado por el MINECO (HAR2013-44342). Mi deseo es dedicárselo al profesor Belda Navarro, mi maestro.

2 RODRÍGUEZ MOÑINO, Antonio, 1965, pp. 23 y ss.; PÉREZ SÁNCHEZ, Alfonso Emilio, 1986, pp. 54-66; ANGULO íñIGUEZ, Diego y PÉREZ SÁNCHEZ, Alfonso Emilio, 1988; BONET CORREA, Antonio, 1993; MCDONALD, Mark P., 2012.

${ }^{3}$ Caso diferente sería el Tratado de la pintura sabia de Fray Juan Ricci de 1650, que, aunque contiene un gran número de dibujos antropométricos, no puede considerarse una cartilla de dibujo, sino un tratado de pintura con ilustraciones. RICCI, Fray Juan, 1650, reed. 1930.

${ }^{4}$ CALVO SERRALLER, Francisco, 1981, pp. 297-302; RUBIN, Laurie et al., 1984; VEGA, Jesusa et al., 1989; BOLTEN, Jaap, 1985; MCDONALD, Mark P., 2002, p. 22 y especialmente el Diálogo V de Carducho: "Trátase del modo de juzgar de las pinturas, singularidad de la perspectiva; qué es dibujo y qué el colorido...", CARDUCHO, Vicente, 1633 (ed.); CALVO SERRALLER, Francisco, 1979, pp. 217-256 y en Pacheco: "Del debuxo y de sus partes", PACHECO, Francisco, 1649 (ed.); BASSEGODA, Bonaventura, 1990, pp. 341-351.

5 VEGA, Jesusa, 1989; MATILLA, José Manuel, 1989; BORDES, Juan, 1992; BORDES, Juan, 1995, pp. 393-428; CORTÉS, Valeria, 1994; ESPINÓS DÍAZ, Adela, 1997; NAVARRETE PRIETO, Benito, 2006; GUTIÉRREZ PASTOR, Ismael, 2008, pp. 37-51; RUIZ ORTEGA, Manuel, 1999.

${ }^{6}$ ALBERTI, Romano, 1604, p. 5; ALLORI, Alessandro, en: BAROCCHI, Paola (ed.), 1971-1977, vol 2. pp. 1941-1981.

7 MARTínEZ, Jusepe, 1675 (ed.), 2006, p. 157; PALOMINO, Antonio, 1715, ed. 1947, I, 1. IV, pp. 448-449. 
transmitir pasiones y para ello era fundamental que se instruyesen en una amplia formación en la que se incluían los estudios fisiognómicos. ${ }^{8}$

Aunque es cierto que las teorías fisiognómicas habían estado durante mucho tiempo ligadas a la mántica y la adivinación y eran perseguidas por la iglesia, ello no fue obstáculo para que sus postulados se introdujesen en la teoría artística europea. En Europa, la fisiognomía había sido incluida, junto con las teorías de la expresión de las pasiones o pathognomía, en los tratados de Leonardo da Vinci, Lomazzo, Gaurico o Francisco de Holanda, había sido el tema central de una de las más célebres conferencias de Le Brun en el seno de la Academia Francesa y en España había sido una materia destacada en los tratados de Carducho, Pacheco o Jusepe Martínez. ${ }^{9}$ Del mismo modo que en estos textos se insistía en su utilidad para desvelar el interior del ser humano y se brindaban descripciones fisiognómicas, las cartillas de dibujo recogieron algunos de estos ejemplos entre sus hojas. Así, se observa que en Scuola perfeta de los Carracci se realizaban ejercicios de rostros gritando y se ofrecían modelos para aprender a representar rostros de tipos humanos como la niña/inocencia, el viejo/lujuria, santa lucía/castidad o San Francisco/devoción; en la cartilla de Fialleti II vero modo se muestra cómo representar sentimientos como el dolor, la sorpresa, la admiración y algunas cabezas grotescas y en el Livre de portraiture de Guercino el pintor realiza su autorretrato con una intencionalidad de marcado carácter psicológico, recogiendo distintas actitudes como la contemplación o la reflexión. ${ }^{10}$

Esta preocupación por ofrecer la imagen de los distintos caracteres del ser humano, así como de las pasiones sentidas en el alma, se haya también en las cartillas españolas. El ejemplo de Ribera recogiendo esta tradición en la composición de sus célebres bocas gritando y sus cabezas grotescas es paradigmático, ${ }^{11}$ así como la gran cantidad de dibujos que realiza García Hidalgo para mostrar la expresión en los ojos. ${ }^{12}$ Pero, en este sentido, resulta aún más interesante la obra del valenciano Vicente Salvador Gómez en el que la fisiognomía aparece como tema fundamental de los restos de la cartilla que ha llegado hasta nuestros días. Esta cartilla, aunque mencionada con anterioridad por otros autores, no ha sido aún analizada en profundidad y hasta la fecha, no se tiene constancia de que se haya realizado la identificación y el estudio de sus fuentes. ${ }^{13}$

\section{La cartilla de Vicente Salvador Gómez}

El único ejemplar conocido de la cartilla de Vicente Salvador Gómez se encuentra en la Real Biblioteca de Madrid. En la actualidad, bajo la signatura BPR II/3727 se conservan en la biblioteca diez hojas, de 22,5 x $16 \mathrm{~cm}$, con encuadernación moderna en las que se incluyen textos manuscritos y dibujos a pluma. ${ }^{14}$ Por las noticias que tenemos, parece improbable que llegase a ser publicada, por lo que podemos suponer que estas hojas formarían parte de un proyecto, que quedó inconcluso con un mayor o menor grado de desarrollo y que nunca llegó a ver la imprenta.

En los últimos años, las distintas contribuciones de Navarrete, Salort y Marco han ido desvelando la biografía de Vicente Salvador Gómez. ${ }^{15}$ Sus trabajos vienen a confirmar algunos de los datos que ya fueron recogidos por Ponz, Orellana y Ceán. ${ }^{16} \mathrm{~A}$ grandes rasgos, se sabe que Vicente Salvador Gómez (Valen-

\footnotetext{
8 ALBERO MUÑOZ, María del Mar, 2016, pp. 140-165.

9 Para una visión en profundidad de la importancia concedida a la fisiognomía y a la expresión de las pasiones durante el siglo XVII vid. DESJARDINS, Lucie, 2000 y PINAULT, Madeleine, 1995, pp. 317- 319.

10 CARRACCI, Annibale, 1599; FIALETTI, Odoardo, 1608 y 1611 y GUERCINO, 1642.

11 Aunque en este punto habría que contextualizar a Ribera en la atmósfera cosmopolita de Roma y Nápoles, donde entró en contacto directo con las nuevas corrientes artísticas italianas.

12 GARCÍA HIDALGO, José, 1693, Prólogo, fol. 5 (9). "Traygo solo el modo para ojos perfectos, y hermosos, sin afectos raros; de suerte, que pueden servir para imagenes Sagradas, y Santas: pues saben los curiosos fisonomistas, que son los ojos la parte que mas declara el animo, y el alma. Pues además de estos, que en el libro traigo, ay ojos estravagantes, unos hundidos, otros sin parpados arriba, ó que no se les vén hasta que les cierran, otros muy abiertos, y redondos, que se les ven todas las pupilas, que parecen ojos de locos, ú de bueyes, cavallos, ó pescados (...) Donde verá el curioso los tres afectos, que es, severo, risueño, y llorando, ó pesaroso".

13 SÁNCHEZ CANTÓN, Francisco Javier, 1934, Tomo III, pp. 83 y 90.

14 SALVADOR GÓMEZ, Vicente, Cartilla y fundamentales reglas de pintura..., Valencia, 1674 (BPR II/3727).

15 SALORT PONS, Salvador; LÓPEZ AZORÍN, Ma José y NAVARRETE PRIETO, Benito, 2001, pp. 393-424; NAVARRETE PRIETO, Benito, 1995, pp. 135-140; MARCO GARCÍA, Víctor, 2006.

16 PONZ, Antonio, 1789, ed. 1947; CEÁN BERMUDEZ, Juan Agustín, 1800; DE ORELLANA, Marcos Antonio, ed. 1930. Palomino, sin embargo, no cita a Vicente Salvador Gómez entre los artistas recogidos en El parnaso español pintoresco y laureado, PALOMINO, Antonio, 1715-1724.
} 
cia 1637-1678) fue un pintor valenciano, discípulo de Jerónimo Jacinto de Espinosa, que se desplazó a Madrid en 1668, que es posible que viajase a Italia, que fue Censor de pinturas del Santo Oficio y que poseía una de las bibliotecas más importantes, en cuanto a cantidad y diversidad de títulos de entre las de los pintores del siglo XVII español. ${ }^{17}$

Muy interesante para el estudio de la cartilla es el hecho de que Vicente Salvador Gómez, llegase a ser Académico Mayor del Aula del Convento de Santo Domingo de Valencia, ya que nos permite pensar que esta circunstancia podría haber motivado que siguiese el ejemplo de otros maestros de pintura y hubiese decidido componer una cartilla con la intención de proporcionar a sus propios alumnos unas "fundamentales reglas de pintura" gracias a las cuales y en sus propias palabras "Ilegará uno a ser muy ducho pintor" ${ }^{18}$

Como ya se ha comentado, en la actualidad se conservan en el Palacio Real de Madrid diez folios, con unas medidas de $25^{\prime} 5 \times 16 \mathrm{~cm}$, dibujados a pluma. El texto se encuentra enmarcado en una orla de doble trazo pintada de color verde, con restos de aguada dorada, con los títulos e iniciales capitulares de mayor tamaño, también de color verde.

La importancia de esta cartilla, que hasta la actualidad ha pasado casi desapercibida para los estudiosos, radica en que se trata del primer ejemplo de cartilla de dibujo española cuyo manuscrito original se conserva, si exceptuamos el trabajo de Fran Juan Ricci de 1650. Este hecho, algo absolutamente inusual, permite el estudio de la cartilla en pleno proceso compositivo antes de ser impreso, siendo muy interesante el análisis de los dibujos originales, con su aspecto de inmediatez e incluso de la cuidada grafía del propio autor. Además de ello, la obra de Vicente Salvador es uno de los escasos ejemplos de trabajo híbrido conocido en España en el cual texto y dibujos son utilizados por igual para la enseñanza del dibujo, alcanzando la palabra y la imagen el mismo valor como transmisores del conocimiento artístico. ${ }^{19}$

El primer folio, que contiene el número "1" en la esquina superior derecha, se corresponde con la portada, en la que el título de la obra aparece como Cartilla y fundamentales reglas de pintura, por las cuales llegará uno a ser muy ducho pintor. Bajo este título, se indica el nombre de su autor, algunos datos biográficos, como que es Familiar del Santo Oficio de la Inquisición, su edad, 37 años y la fecha y lugar de impresión, Valencia $1674^{20}$ (Fig. 1).

La segunda hoja, marcada con el número "2", es una dedicatoria a la Virgen María, un ejercicio común entre los autores de la época, máxime si éstos pertenecían al Santo Oficio. Pero quizás, este dato, junto con la ausencia de un patrón a quien dedicar la obra, y por lo tanto que financiase tal empresa, podría explicar que la cartilla, finalmente, nunca fuese publicada ${ }^{21}$ (Fig. 2).

17 ESPINÓS DÍAZ, Adela, 1997, pp. 21-23 y 160-189; GARCÍA MAHÍQUES, Rafael 1996, LXIII, pp. 57-78.

18 La Cartilla fue publicada extractada en SÁNCHEZ CANTÓN, Francisco Javier, 1934, pp. 84-90; PÉREZ SÁNCHEZ, Alfonso Emilio, 1980, pp. 69-78; ÁNGULO ÍNIIGUEZ, Diego y PÉREZ SÁNCHEZ, Alfonso Emilio 1988, n. 402-407; ESPINÓS, Adela, 1994, pp. 159-187; OCAÑA MARTÍNEZ, José Antonio, 2001.

19 Aunque la composición de la cartilla de Pedro Villafranca y Malagón Cartilla para aprender a dibujar es anterior, de 1637 aproximadamente, la conocemos por su publicación, como añadido a la traducción que Patricio Cajés efectuó de la Regola delle cinque ordini d'Architettura, de Vignola (Madrid, 1651). Del ejemplar original sólo quedan algunas hojas sueltas en el Museo de Arte de Cataluña. Entre estos manuscritos híbridos, también debemos mencionar la cartilla de García Hidalgo y el Libro de retratos de Francisco Pacheco, que tampoco llegó a imprimirse en su momento, CACHO CASAL, Marta, 2011.

20 La transcripción del texto de la cartilla se irá incorporando en las notas a pie de página siguiendo el orden establecido en este artículo. Debo agradecer la ayuda prestada por el profesor Beltrán Corbalán en esta transcripción. El texto de la primera página es el siguiente: CARTILLA Y FUNDAMENTALES REGLAS DE PINTU-/ RA por las quales llegará uno a çer mui ducho pintor. Descríuela Vicente Saluador y Gómez, familiar del Santo Ofiçio de la Ynquiçiçión y sçen-/ sor de de las pinturas en çu deçençia y qulto / por el dicho tribunal, et hecha el anno 37 de çu edad y en el de la Vmana Redemçión / del Sennor de 1674, en Valençia. /l

21 DEDICATORIA a la Virgen Madre y Señora nuestra La Reyna de los Ángeles. Mvi antigua costumbre fue de los / escriptores dedicar sus obras / a aquellas personas de quien / más benefiçios y merçedes auí-/an reçebido, y de quien espera-/uan reçebir y alcançar otras / mayores. Y queriendo yo seguir / y imitar esta tan açertada cos-/tumbre, me puçe a conçiderar / de quién auía yo reçebido más benefiçios en esta vida y de / quién esperaua reçebir otros mayores, y hallé ser vos, / VIRGEN santíçima, patrona y madre mía, que de-/xando las merçedes generales que a todo el linage hum-/ano aueys hecho, a mí singularmente me aueys siem-/pre favoresido. Y más çiendo como çoy güestro yndicno / esclauo. Y por ello, ¿a quién sino a ti, Señora, auía yo de di-/rixir estas delineaçiones? Pues siendo emanadas de / tu ixo y mi señor Jesucristo, por lo conçiguiente ce deuen / a ti por lo que ynfluies e inpetras con tu ruego con Dios. / Y pues tú, Señora, eres mi norte, luz y mi gía, gía mi / espíritu y mano para que logre el açierto que nece-/çito para esta obra. La qual, hella y todas quantas / yo hiçiere, sean para tu mayor çeruiçio, y pues er-/es, Señora, el modelo y la norma de la mayor her-/mosura. Alcánçala a mi alma, para que, descriui-/endo mi pluma lo que es pintura, conçiga por e-/lla que todos te pinten (y demuestren en parte) la / divina hermosçura con que el Señor te formó. Y çi esto lo-/grare, optendrá mi hestudio el mayor premio. /l 


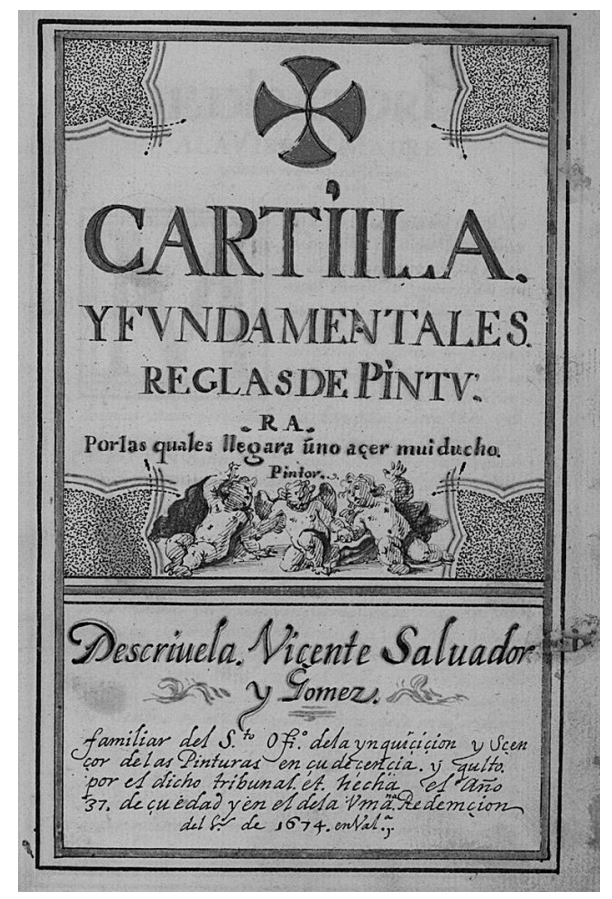

Fig. 1. Vicente Salvador Gómez, Frontispicio de la Cartilla y fundamentales reglas de pintura, Valencia 1674. Biblioteca del Palacio Real de Madrid, () Patrimonio Nacional.

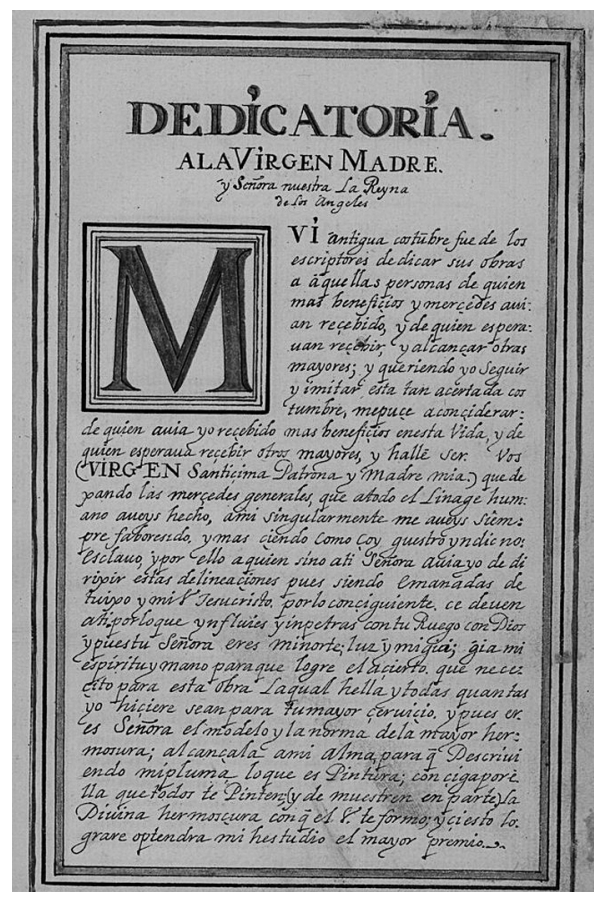

Fig. 2. Vicente Salvador Gómez, Dedicatoria a la Virgen María de la Cartilla y fundamentales reglas de pintura, Valencia 1674. Biblioteca del Palacio Real de Madrid, () Patrimonio Nacional.
La tercera hoja, marcada con el número "4" es donde explica la Razón de la obra. Siguiendo el mismo esquema y orden que había seguido Carducho en sus Diálogos, indica que ésta versará sobre "las reglas de simetría: anatomía, fisiognomía, geometría y perspectiva" ya que su conocimiento es "inexcusable" a todo pintor "científico", aclarando que al final de la obra incluirá una tabla con los tratados artísticos en los que los artistas que así lo necesiten, pueden encontrar estos temas tratados de forma más extensa. La intención declarada por el autor es la de proporcionar un resumen de las cinco reglas que ha- bían sido enunciadas por los grandes tratadistas europeos pero recogidos de una forma mucho más práctica. Para ello, Vicente Salvador se proponía elaborar una síntesis sencilla y clara que explicara de forma comprensible a "los que andan muy en tinieblas" las distintas teorías artísticas que circulaban en ese momento. El autor justificaba la necesidad de publicar esta cartilla debido a que los mencionados tratados se encontraban escritos en otras lenguas, como el alemán, el italiano y el francés, haciéndolos difíciles de entender para la mayoría de los alumnos de su academia22 (Fig. 3).

22 RAÇÓN DESTA obra y motiuo della que da a los letores Viçente Saluador y Gómez. La raçón porque çe descriuen en / esta cartilla las reglas de Çi-/metría, Anatomía, Fhisçonomía, Geometría y Perspectiua, es por-/que son ynesqusables todas sus / operaçiones, al que justamente a / de benirle bien el título onros-/o de pintor. Y por lo dicho, es de en-/tender que al tal le deuen çer / ynesqusables todas sus operaçiones, por çer unos elemen-/tos sin los quales sería ynposçible el çer uno pintor çilentífico, como fuera ynposçible que un ombre tuuiera vi-/da si al dicho le faltasen, si no todos, a lo menos algún ele-/mento de los que es formado. Así pues, tendrá el estudi-/ante en el Arte de Pintura atençión a que los carac-/teres desta cartilla le an de çer norte claro en sus ma-/yores sombras, desterando de su entendimiento toda / dotrina falça. Hescríuese la presente obra en quatro / partes diuidida, y en cada una dellas la dotrina bastan-/te para la educaçión (la que podrá apeteçer más dilatada) / la podrá conçeguir en los autores que allará al final en la tabla / a lo último destos tratados. Los cuales uan dispuestos en / 4 diálogos para que, auiendo quien dude, aya quien / declare lo que anda muy en tinieblas, assí porque la mayor / parte de los autores que an escrito de la pintura / lo an echo cada qual en su edioma, como por ser las más a-/lemanas, ytalianas, françesça, y la mayor parte de lo es-/crito, cosas teóricas. Y los que tratan de la plática, cada uno / entiende çer el mexor, lo que io no pretendo en mi obra, por-/que a todos uenero como a mis maestros. De todo lo bueno es / Dios autor y de todas las faltas lo a sido mi ynsufiçençia. / Vale. // Para la alfabetización de los artistas españoles sigue siendo válido MARTín GONZÁLEZ, Juan José, 1984, pp. 222-224 y 1985, pp. 32 y ss. Para su formación intelectual vid. BELDA NAVARRO, Cristóbal, 2002, pp. 48-50 y BELDA NAVARRO, Cristóbal, 2008, pp. 211-222. 


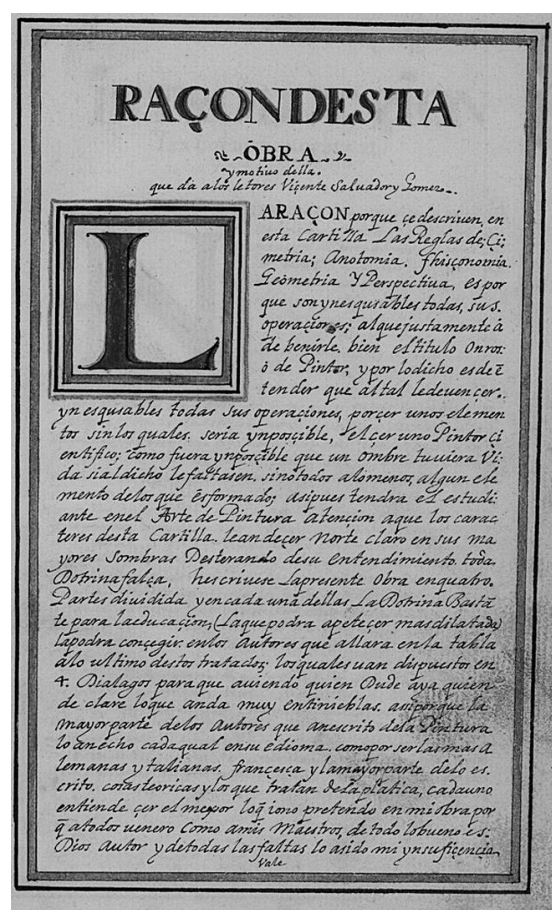

Fig. 3. Vicente Salvador Gómez, Justificación de la Cartilla y fundamentales reglas de pintu$r a$, Valencia 1674. Biblioteca del Palacio Real de Madrid, () Patrimonio Nacional.

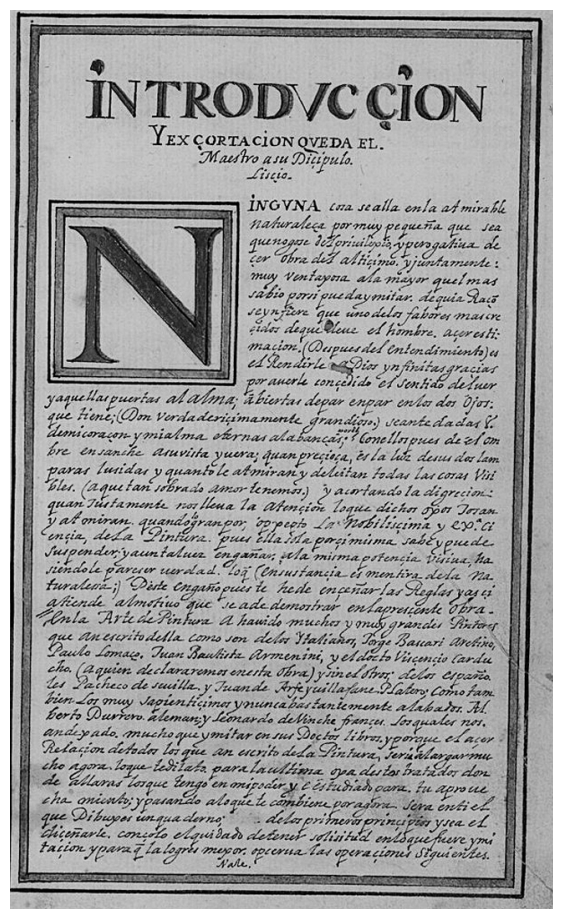

Fig. 4. Vicente Salvador Gómez, Introducción de la Cartilla y fundamentales reglas de pintu$r a$, Valencia 1674. Biblioteca del Palacio Real de Madrid, (c) Patrimonio Nacional.

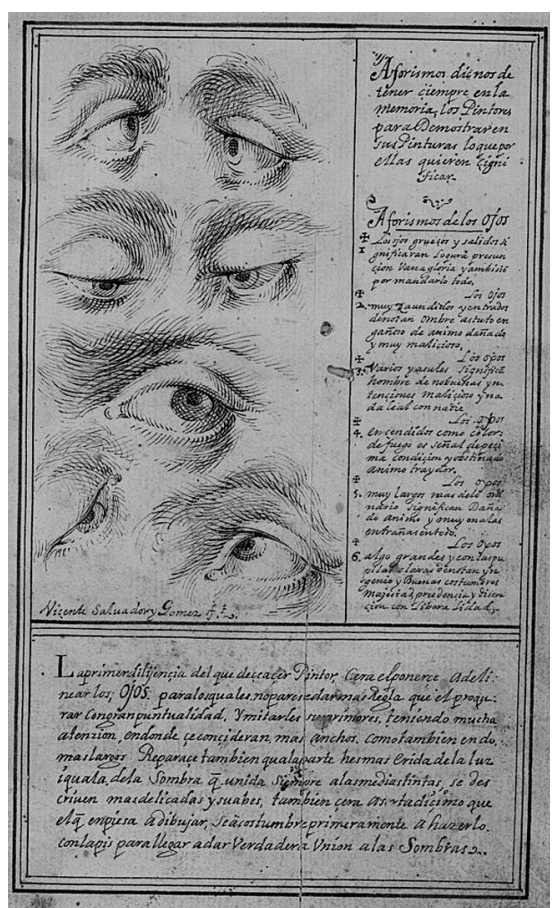

Fig. 5. Vicente Salvador Gómez, Ojos. Cartilla y fundamentales reglas de pintura, Valencia 1674. Biblioteca del Palacio Real de Madrid, () Patrimonio Nacional.
En la cuarta página, marcada con el número " 5 ", la Introducción, es donde Vicente Salvador da cita a los autores a los que ha recurrido como fuentes del tratado, afirmando que no solo había consultado sus textos sino que además éstos eran de su propiedad. En concreto cita a los "italianos, Jorge Vasari Aretino, Paulo Lomazzo, Juan Bautista Armenini, y el docto Vicenzio Carducho", de los españoles "Pacheco de Sevilla y Juan de Arfe y Villafañe, Platero" y también "los muy sapientísimos y nunca bastantemente alabados Alberto Durero, alemán; y Leonardo de Vinci, francés" sin llegar a mencionar a todos por no querer alargarse pero de los que afirma "los que tengo en mi poder y he estudiado para tu aprovechamiento" ${ }^{23}$ (Fig. 4).

Las siguientes seis hojas, numeradas del " 6 " al "11", están dedicadas a los rasgos del rostro, siguiendo con el orden habitual que partía de los ojos para continuar con la nariz, la boca, las ore-

${ }^{23}$ INTRODVCÇIÓN y exçortación qve da elmaestro a su diçípulo Lisçio Ninguna cosa se alla en la atmirable / naturaleça por muy pequeña que sea / que no gose del priuilexio y perogatiua de / çer obra del Altíçimo y juntamente / muy ventaxosa a la mayor quel más / sabio por sí pueda ymitar. De quia raçón / se ynfiere que uno de los fabores más cre-/çidos de que deue el hombre açer esti-/maçión (después del entendimiento) es / el rendirle [a] Dios ynfinitas graçias / por auerle conçedido el sentido del uer / y aquellas puertas al alma, abiertas de par en par en los dos ojos / que tiene (don verdaderíçimamente grandioso). Sean te dadas, Señor, / de mi coraçón y mi alma eternas alabanças. «> Con ellos pues dé el om-/bre ensanche a su vista y uerá quán preçiosa es la luz de sus dos lám-/paras lusidas y cuánto le atmiran y deleitan todas las cosas visi-/bles (a que tan sobrado amor tenemos). Y acortando la digreçión, / quán justamente nos lleua la atención lo que dichos oxos josan / y atmiran cuando <lo>gran por opxepto la nobilísçima y exçelentíçima ci-/ençia de la pintura. Pues ella sola por çí misma sabe y puede / suspender, y aun tal uez engañar, a la misma potençia visiua, ha-/siéndole pareser uerdad lo que en sustançia es mentira de la na-/turalessa. Deste engaño pues te he de ençeñar las reglas y asçí / atiende al motiuo que se a de demostrar en la presçente obra. / En la arte de pintura a hauido muchos y muy grandes pintores / que an escrito della, como son de los ytalianos Jorge Basçari, Aretino, / Paulo Lomaço, Juan Bautista Armenini y el docto Viçençio Cardu-/cho (a quien declararemos en esta obra), y sin él otros; de los españo-/les, Pacheco de Seuilla y Juan de Arfe y Uillafane, platero; como tam-/bién los muy sapientíçimos y nunca bastantemente alabados Al-/berto Durrero, alemán, y Leonardo de Vinche, francés. Los quales nos / han dexado mucho que ymitar en sus doctos libros. Y porque el açer / relaçión de todos los que an escrito de la pintura sería alargar mu-/cho agora, lo que te dilato para la última oxa destos tratados don-/de allarás los que tengo en mi poder y e estudiado para tu aproue-/chamiento. Y pasando a lo que te combiene por agora, será en ti el / que dibuxes un quaderno de los primeros prinçipios y sea el / diçeñarle con çolo el quidado de tener solisitud en lo que fuere ymi-/taçión. Y para que la logres mexor, opçerua las operaçiones siguientes. Vale. /I 
jas, la cabeza y las manos y una última hoja, numerada con un "18" la destina a realizar un Sumario acerca de la proporción.

Buscando otorgar una ordenación compositiva a la cartilla, su original estructura divide las hojas en tres zonas. La zona superior derecha contiene los rasgos físicos, distribuidos con distinta regularidad y distinto número de imágenes (en concreto dibuja nueve narices, siete bocas, siete ojos y tres orejas) y a su lado, en una segunda zona, aparecen enumerados una serie de aforismos que describen la forma en relación con el carácter de cada tipo humano. La parte inferior de la hoja, de forma apaisada y ocupando algo menos de un tercio del total del papel, se destina a la descripción literaria de cómo se ha de aprender a dibujar cada parte del rostro.

Analizando estos dibujos y estudiando los textos que los acompañan, se observa que lo que se conserva de la cartilla es concretamente el inicio de la parte dedicada a la fisiognomía y no a la simetría, proporción, anatomía o geometría. El autor, y aquí radica la mayor novedad, ejemplifica cada parte del rostro con una serie de dibujos y aforismos que, según afirma, toma de Aristóteles, estableciendo la relación existente entre el carácter de una persona y su aspecto físico. Para ello, describe distintos tipos de ojos, narices, bocas, orejas, cabezas y manos propios de seres malvados, entre los que se encuentran los lujuriosos, traidores, avaros, codiciosos, coléricos, vanidosos, y también aquellos rasgos que corresponden a los caracteres de los justos, como los leales, fuertes, sagaces, ingeniosos, liberales, bondadosos o prudentes. Sin embargo, y a pesar de que recoge en su cartilla un gran número de sentencias fisiognómicas, se observa que los dibujos no se corresponden exactamente con to- dos estos ejemplos. En las hojas dedicadas a los ojos y a las bocas, las únicas partes del rostro que gracias a su movimiento pueden cambiar su expresión, tan solo ilustra con dibujos aquellos correspondientes a los caracteres virtuosos, ya que, siguiendo los postulados trentinos, muy arraigados en España en este momento, éstas son las convenientes a las figuras sagradas.

Así, en la hoja dedicada al estudio de los ojos, y aunque en los aforismos se detiene en la descripción de seis tipos humanos, entre los que incluye al ambicioso, malicioso, desleal, traidor y malvado, todos los dibujos se corresponden con el mismo tipo, el hombre justo, prudente, ingenioso y liberal que presenta en sus rasgos físicos un gran equilibrio, prototipo de individuo santo y virtuoso. ${ }^{24}$ Para ello dibuja un ojo armónico y proporcionado, de tamaño medio, con la pupila clara, una inclinación nivelada y una expresión serena y templada que es representado recreando las distintas posibilidades de movimiento del globo ocular y de la abertura palpebral, dirigiendo la mirada a distintos puntos: al frente, ligeramente hacia abajo, levemente hacia arriba y claramente hacia arriba ${ }^{25}$ (Fig. 5).

A los ojos les sigue la nariz. En la sexta hoja, Vicente Salvador sigue el mismo esquema realizando nueve dibujos, pero en este caso de distintos tipos de nariz. Una nariz proporcionada vista de forma lateral con el tabique recto, otra con joroba ósea, otra de perfil aguileño, con el ángulo nasolabial agudo, y otras que ejemplifican distintos tipos de orificios y puntas nasales en escorzo y desde un punto de vista inferior, incluyendo la descripción del tipo moderado, en el que "los dos agujeros respiraderos" son desiguales, señal inequívoca, según estos aforismos, del hombre de carácter liberal e ingenioso ${ }^{26}$ (Fig. 6).

\footnotetext{
${ }^{24}$ Aforismos dicnos de / tener çiempre en la / memoria los pintores / para demostrar en / sus pinturas lo que por / ellas quieren çigni-/ficar. /Aforismos de los ojos 1. Los ojos grueços y salidos si-/gnificarán loqura, presun-/çión, vanagloria y ambisión / por mandarlo todo. /2. Los ojos / muy raundidos y entrados / denotan ombre astuto, en-/gañoso, de ánimo dañado / y muy malicioso. /3. Los oxos / varios y asules significan / hombre de no buenas yn-/tençiones, maliçioso y na-/da leal con nadie. /4. Los oxos / ençendidos como color / de fuego es señal de péci-/ma condiçión y obstinado / ánimo traydor. /5. Los oxos / muy largos, más de lo ordi-/nario significan daña-/do ánimo y muy malas / entrañas en todo. /6. Los oxos / algo grandes y con las pu/pilas claras denotan yn-/genio y buenas costumbres, majestad, prudençia y discre-/çión con liberalidad. /La primera diligençia del que deçea çer pintor çerá el ponerçe a deli-/near los osos, para los quales no parese dar más regla que el proqu-/rar con gran puntualidad ymitarles su[s] primores, teniendo mucha atenzión en donde çe conçideran más anchos, como también en do / más largos. Repárese también quála parte es más erida de la luz / i quála de la sombra, que unida siempre a las medias tintas, se des-/criuen más delicadas y suabes. También çerá asertadíçimo que / el que enpiesa a dibujar se acostumbre primeramente a hazerlo / con lapis para llegar a dar verdadera vnión a las sombras.// En los tratados o textos sobre fisiognomía, los ojos y las cejas siempre son considerados las zonas del rostro donde se concentra una mayor carga expresiva. La direccionalidad de los ojos, su forma, su tamaño, su color, la distancia entre ellos, y así mismo, la forma de las cejas, su espesura, el entrecejo y su color, han sido los aspectos a los que se han dedicado más líneas en estos escritos.

${ }^{25}$ En estos aforismos, Vicente Salvador describe las características físicas de seis tipos de ojos en relación con sus características morales, pero tan solo emplea los dibujos para ejemplificar los del ingenioso, prudente y liberal.
} 


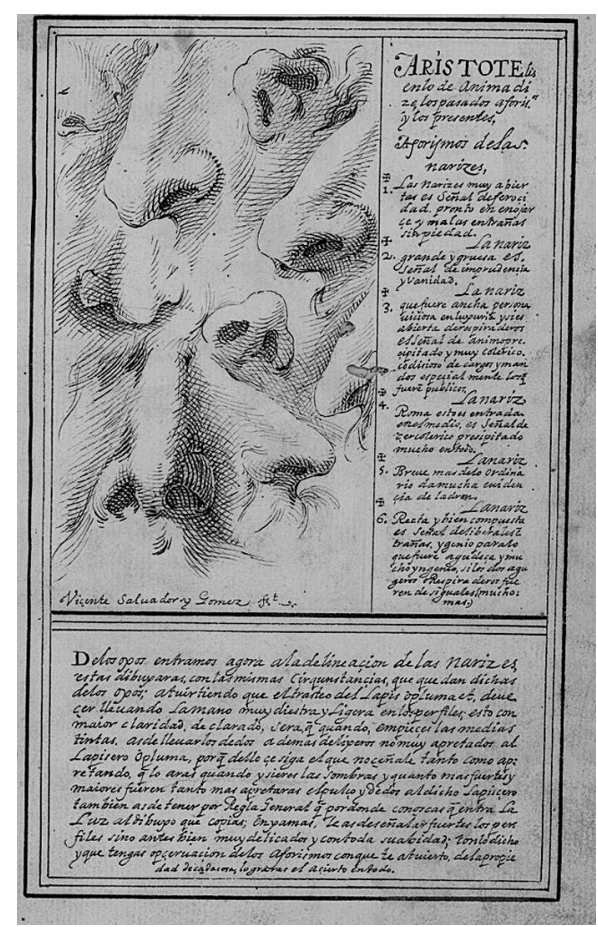

Fig. 6. Vicente Salvador Gómez, Narices. Cartilla y fundamentales reglas de pintura, Valencia 1674. Biblioteca del Palacio Real de Madrid, () Patrimonio Nacional.

Vicente Salvador considera que el segundo rasgo de un rostro bello radica en la forma de la boca y a ella dedica la séptima hoja. Siguiendo el mismo criterio utilizado con los ojos, de entre los seis aforismos, se inclina por representar, la "boca mediana y de buen color" que se corresponde con el

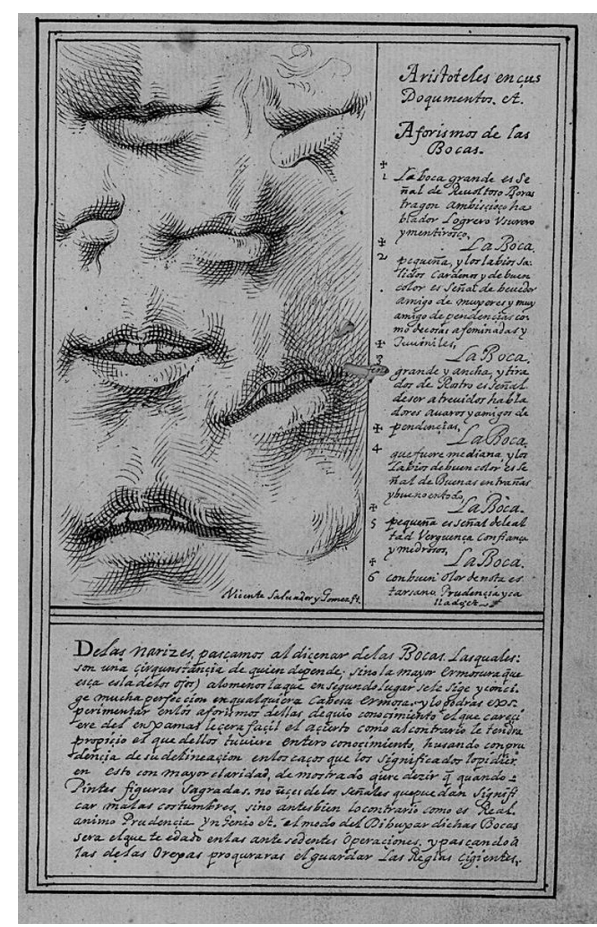

Fig. 7. Vicente Salvador Gómez, Bocas. Cartilla y fundamentales reglas de pintura, Valencia 1674. Biblioteca del Palacio Real de Madrid, (c) Patrimonio Nacional.

carácter bondadoso. Para ello realiza siete dibujos del mismo tipo de boca, con las comisuras labiales elevadas, en un gesto de tímida sonrisa y con dos variantes. La primera con los labios juntos y la boca cerrada y la segunda con la boca entreabierta, mostrando los dientes ${ }^{27}$ (Fig. 7).

${ }^{26}$ ARISTÓTELES, en lo de Ánima, di-/ze los pasados aforismos / y los presentes. / Aforismos de las / narizes 1. Las narizes muy abier-/tas es señal de feroçi-/dad, pronto en enojar-/çe y malas entrañas / sin piedad. / 2. La nariz / grande y gruesa es / señal de imprudençia / y vanidad. / 3. La nariz / que fuere ancha, persona / uiçiosa en luxuria. Y si es / abierta de respiraderos, / es señal de ánimo preçipitado y muy colérico, / codisioso de cargos y man-/dos, espeçialmente los que / fueren públicos. / 4. La nariz / roma, esto es, entrada / en el medio, es señal de / çer colérico, presipitado mucho en todo. / 5. La nariz / breue, más de lo ordina-/rio, da mucha euiden-/çia de ladrón. / 6. La nariz / recta y bien compuesta / es señal de liberales en-/trañas y genio para lo / que fuere, agudeça y mu-/cho yngenio, si los dos agu-/geros respiraderos fue-/ren desiguales (mucho / más). / De los oxos entramos agora a la delineaçión de las narizes. / Éstas dibuxarás con las mismas cirqunstançias que quedan dichas / de los oxos, aduirtiendo que el trasteo del lapis o pluma et deue / çer lleuando la mano muy diestra y ligera en los perfiles. Esto con / maior claridad declarado será que cuando empieçes las medias / tintas as de lleuar los dedos, además de lixeros, no muy apretados al / lapisero o pluma, porque dello çe siga el que no çeñale tanto como ap-/retando, que lo arás cuando ysieres las sombras. Y quanto más fuertes y / maiores fueren, tanto más apretarás el pulço y dedos al dicho lapisçero. I

También as de tener por regla general que por donde conoscas que entra la / luz al dibuxo que copias, en xamás le as de señalar fuertes los per-/files, sino antes bien muy delicados y con toda suabidad. Con lo dicho y que tengas opçeruaçión de los aforismos con que te atuierto de la propie-/dad de cada cosa, lograrás el açierto en todo.//

${ }^{27}$ Aristóteles en çus / doqumentos etcétera Aforismos de las bocas 1. La boca grande es se-/ñal de reuoltoso, borás, / tragón, ambiçioço, ha-/blador, logrero, vsurero / y mentirosço. / 2. La boca pequeña y los labios sa-/lidos, cárdenos y de buen / color es señal de beuedor, / amigo de muxeres y muy / amigo de pendençias co-/mo de cosas afeminadas y / juueniles. / 3. La boca / grande y ancha y tira-/dos de rostro es señal / de ser atreuidos, habla-/dores, auaros y amigos de / pendençias. / 4. La boca / que fuere mediana y los / labios de buen color es se-/ñal de buenas entrañas / y bueno en todo. / 5. La boca / pequeña es señal de leal-/tad, vergüença, confiança / y medrosos. 6. La boca / con buen olor denota es-/tar sano, prudençia y ca-/llado, etçétera. I De las narizes pasçamos al diçenar de las bocas. Las quales / son una çirqunstançia de quien depende, si no la mayor ermosura (que / esça es la de los ojos), a lo menos la que en segundo lugar se le sige y conci-/ge mucha perfecçión en qualquiera cabesa ermosa. Y lo podrás eso s-/perimentar en los aforismos dellas, de quio conoçimiento el que careçi-/ere dél, en xamás le çerá 


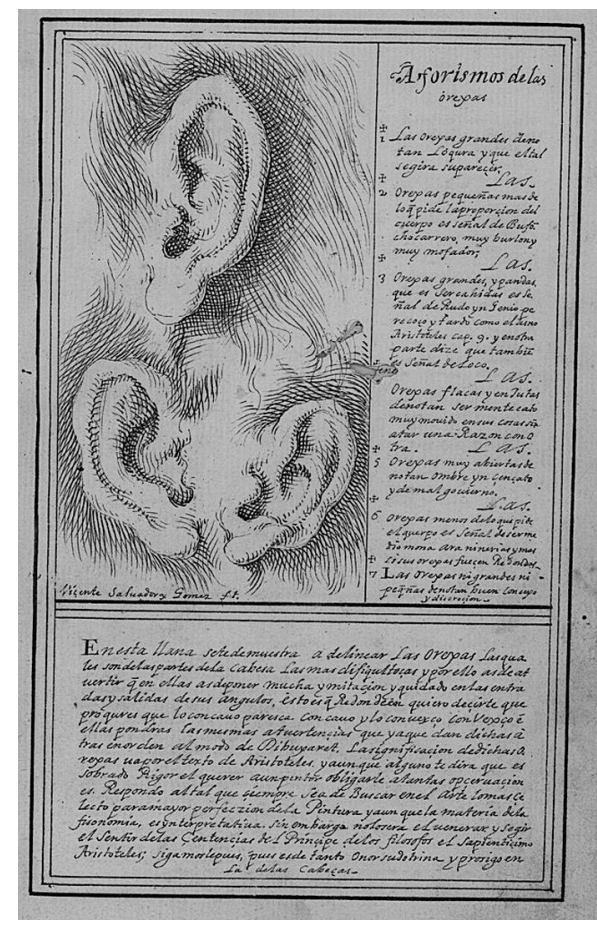

Fig. 8. Vicente Salvador Gómez, Orejas. Cartilla y fundamentales reglas de pintura, Valencia 1674. Biblioteca del Palacio Real de Madrid, () Patrimonio Nacional.

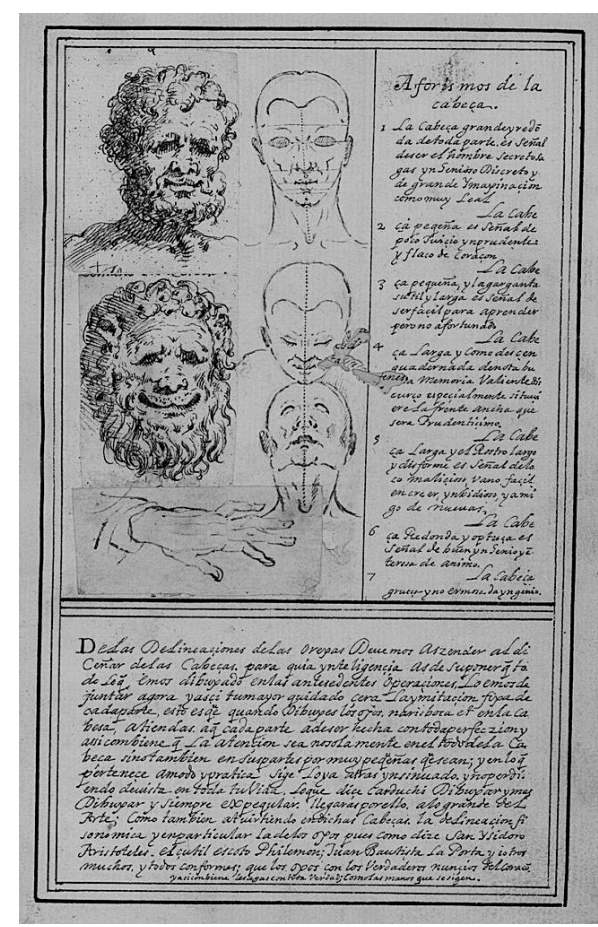

Fig. 9. Vicente Salvador Gómez, Cabezas. Cartilla y fundamentales reglas de pintura, Valencia 1674. Biblioteca del Palacio Real de Madrid, (c) Patrimonio Nacional.
La octava hoja la dedica a mostrar los distintos tipos de orejas. El autor realiza para ello tan solo tres dibujos, aunque escribe siete aforismos. En este caso es muy difícil distinguir a qué aforismo o tipo humano corresponden las orejas, ya que las diferencias que establece entre un tipo y otro se basan en gran medida en su tamaño y proporción con respecto al conjunto de rasgos del rostro. En esta ocasión, las orejas que decide representar co- rresponderían a un varón de mediana edad con unos lóbulos muy marcados ${ }^{28}$ (Fig. 8).

De una mayor relevancia se muestra la novena hoja, la correspondiente a la representación de la cabeza. Para ejemplificar los distintos tipos, Vicente Salvador enuncia siete sentencias fisiognómicas pero lo verdaderamente interesante en este caso son los dibujos y esquemas que realiza. Para ello,

fáçil el açierto. Como al contrario, le tendrá / propiçio el que dellos tuuiere entero conoçimiento, husando con pru-/dençia de su delineaçión en los casos que los significados lo pidier-/en. Esto, con mayor claridad demostrado, quiere dezir que, quando / pintes figuras sagradas, no uçes de los señales que puedan signifi-/car malas costumbres, sino antes bien lo contrario, como es real / ánimo, prudençia, yngenio, etçétera. El modo del dibuxar dichas bocas / será el que te e dado en las antesedentes operaçiones y, pasando a / las de las orexas, procurarás el guardar las reglas çigientes. //

28 Aforismos de las / orexas 1. Las orexas grandes deno-/tan loqura y que el tal / segirá su pareçer. / 2. Las / orexas pequeñas, más de / lo que pide la proporçión del / cuerpo es señal de bufón, / chocarrero, muy burlón y / muy mofador. / 3. Las / orexas grandes y pandas, / que es ser cahídas, es se-/ñal de rudo yngenio, pe-/recoso y fardón, como el asno / (Aristóteles, capítulo 9); y en otra / parte dize que también / es señal de loco. / [4] Las / orexas flacas y enjutas / denotan ser mentecato, / muy mouido en sus cosas, sin / atar una razón con o-/tra. 5. Las / orexas muy abiertas de-/notan ombre ynçençato / y de mal gouierno. / 6 . Las / orexas menos de lo que pide / el querpo es señal de ser me-/dio mona, ará ninerías, y más / si sus orexas fueçen redondas. 17. Las orexas ni grandes ni / pequeñas denotan buen consexo / y discreçión. / En esta llana se te demuestra a delinear las orexas, las qua-/les son, de las partes de la cabesa, las más difiqultoças y por ello as de at-/uertir que en ellas as de poner mucha ymitaçión y quidado en las entra-/das y salidas de sus ángulos, esto es, que redondeen. Quiero deçirte que / proqures que lo cóncauo paresca cóncauo, y lo conuexço, convexo; en / ellas pondrás las mesmas atuertençias que ya quedan dichas a-/trás en orden al modo de dibuxar, etçétera. La significaçión de dichas o-/rexas ua por el texto de Aristóteles y, aunque alguno te dirá que es / sobrado rigor el querer a un pintor obligarle a tantas opçeruaçion-/es, respondo al tal que çiempre se a de buscar en el arte lo más çe-/lecto para mayor perfeczión de la pintura. Y aunque la materia de la / fisionomía es ynterpretatiua, sin embargo no lo será el uenerar y segir / el sentir de las çentençias del prínçipe de los filósofos, el sapientíçimo Aristóteles. Sigámosle pues, pues es de tanto onor su dotrina, y prosigo en / la de las cabeças. // 
copia por un lado los escorzos o proyecciones ortogonales de la cabeza realizadas por Durero, escogiendo el mismo tipo de hombre, de complexión atlética, con una cabeza un tanto alargada, pero proporcionada. $Y$ de entre todas las cabezas realizadas por Della Porta en su obra Fisiognomía dell huomo, copia la cabeza del hombre-león, ejemplo de hombre magnánimo, prudente y valiente ${ }^{29}$ (Fig. 9).

La décima hoja está incompleta. Sabemos que está dedicada a las manos porque enuncia siete aforismos sobre ellas, cuatro sobre los dedos y cuatro sobre las uñas. Sin embargo, el único dibujo que aparece, está situado en el margen inferior. Se trata del extremo de tres dedos que no nos permiten interpretarlos. Además hay una inscripción que nombra a "Ribera" dentro del cuadrante de los dibujos. Esta inscripción está escrita con una caligrafía y tinta diferentes al resto de la cartilla, pero con la información que tenemos actualmente, tiene una difícil interpretación ${ }^{30}$ (Fig. 10).

La última página está numerada con un "18" en la esquina superior derecha como las anteriores. En esta hoja titulada «Sumario» el autor comien-

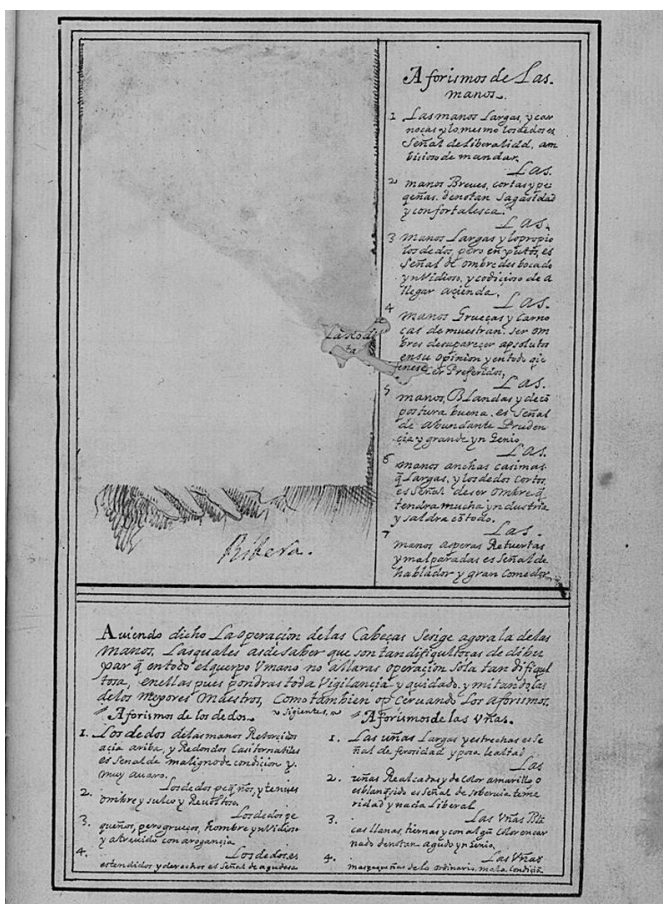

Fig. 10. Vicente Salvador Gómez, Manos. Cartilla y fundamentales reglas de pintura, Valencia 1674. Biblioteca del Palacio Real de Madrid, () Patrimonio Nacional.

${ }^{29}$ Aforismos de la / cabeça 1. La cabeça grande y redon-/da de toda parte es señal / de ser el hombre secreto, sa-/gaz, ynhenioso, discreto y / de grande ymaxinaçión, / como muy leal. / 2. La cabe-/ça pequeña es señal de poco juiçio ynprudentes / y flaco de coraçón. /3. La cabe-/ça pequeña y la garganta sutil / y larga es señal de / ser fáçil para aprender pero no afortunado. 14. La cabe-/ça larga y como desçen-/quadernada denota bu-/[en]a memoria, valiente dis-/curso, espeçialmente si tuui-/ere la frente ancha, que / será prudentíçimo. 15. La cabe-/ça larga y el rostro largo / y disforme es señal de lo-/co maliçioso, vano, fáçil / en creer, ynbidioso y ami-/go de nueuas. /6. La cabe-/ça redonda y optuça es / señal de buen inhenio y en-/teresa de ánimo. //7. La cabeça / grueça y no ermosa da yngenio. /De las delineaçiones de las orexas deuemos aszender al di-/ceñar de las cabeças, para quia ynteligençia as de suponer que to-/do lo que emos dibuxado en las antesedentes operaçiones lo emos de $/$ juntar agora. Y asçí, tu mayor quidado çerá la ymitaçión fixa de / cada parte. Esto es, que cuando dibuxes los ojos, naris, boca, etçétera en la ca-/besa, atiendas a que cada parte a de ser hecha con toda perfeczión, y / assí combiene que la atençión sea no solamente en el todo de la ca-/beça, sino también en sus partes, por muy pequeñas que sean.Y en lo que / perteneçe a modo y prática, sige lo ya atrás ynsinuado y no perdi-/endo de uista en toda tu vida lo que dice Carduchi: dibuxar y más / dibuxar y siempre expeqular, llegarás por ello a lo grande del / Arte. Como también atuirtiendo en dichas cabeças la delineaçión fi/sonómica y, en particular, la de los oxos. Pues como dize san Ysidoro, / Aristóteles, el çutil Escoto, Philemon, Juan Bautista la Porta y otros / muchos, y todos conformes, que los ojos çon los verdaderos nunçios del coracón, / y así combiene los agas con toda verdad, como las manos que se sigen. //

30 Aforismos de las / manos 1. Las manos largas y car-/noças y lo mesmo los dedos es / señal de liberalidad, am-/bisioso de mandar. / 2. Las / manos breues, cortas y pe-/queñas denotan sagasidad / y con fortalesca. / 3. Las / manos largas y lo propio / los dedos, pero enxutos, es / señal de ombre desbocado, / ynvidioso, y codiçioso de a-/llegar açienda. / 4. Las / manos grueças y carno-/ças demuestran ser om-/bres de su pareçer, apsolutos en su opinión y en todo qui-/[eren] [ç]er preferidos. / 5. Las / manos blandas y de com-/postura buena es señal / de abundante pruden-/çia y grande yngenio. / 6. Las / manos anchas, casi más / que largas, y los dedos cortos / es señal de ser ombre que / tendrá mucha yndustria / y saldrá con todo. /7. Las / manos ásperas, retuertas / y mal paradas son señal de / hablador y gran comedor. / Auiendo dicho la operaçión de las cabeças, se sigue agora la de las / manos. Las quales as de saber que son tan dificultoças de dibu-/xar que en todo el querpo vmano no allarás operaçión sola tan difiqul-/tosa. En ellas pues pondrás toda vigilançia y quidado, ymitándolas / de los mayores maestros, como también opçeruando los aforismos / sigientes: (columna 1) Aforismos de los dedos 1. Los dedos de las manos retorçidos / açia arriba y redondos, casi tornatiles, / es senal de maligno de condiçión y / muy auaro. / 2. Los dedos pequeños y tenues, / hombre y sulco y reuoltoso. / 3. Los dedos pe-/queños pero grueços, hombre ynvidioso / y atreuido con arrogançia. 4. Los dedos es/tendidos y derechos es señal de agudesa. / (columna 2) Aforismos de las vñas 1. Las uñas largas y estrechas es se-/ñal de ferosidad y poca lealtad. /

2. Las / uñas realzadas y de color amarillo o esblanquido es señal de soberuia, teme-/ridad y nada liberal. /

3. Las uñas blan-/cas, llanas, tiernas y con algún color encar-/nado denotan agudo ynhenio. / 4. Las uñas / más pequeñas de lo ordinario, mala condiçión. //. Como un simple ejercicio de elucubración, se podría interpretar que esta inscripción, realizada con posterioridad, tal como indica su tipo de grafía, quizás indicaba el ejemplo de Ribera como modelo para la realización de las manos, pero insisto en que con ese dato aislado es muy aventurado formular otra teoría. 
za la sección con un estudio de las proporciones del cuerpo humano citando a Plinio, Durero y Juan de Arfe, de quienes tomó las diferentes medidas que presenta de forma extractada, aunque detallada ${ }^{31}$ (Fig. 11).

Del resto de las hojas que faltan para completar la cartilla no se tiene constancia, pero el hecho de que la numeración llegue hasta el número 18, podría indicar que se llegaron a realizar pero en la actualidad se encuentran desaparecidas o extraviadas. En el Museo del Prado se encuentra una hoja suelta que por sus características y medidas podría ser considerada un dibujo preparatorio para comenzar el capítulo de la simetría. Esta hoja ( $n^{\circ}$ FD-850) es de un tamaño algo menor que el resto del cuaderno $(24 \times 15 \mathrm{~cm}$ y está dibujada por ambas caras. En el anverso aparece pintada una figura sentada y el busto de otra, junto con anotaciones numéricas y a su izquierda una aguada de Venus y Cupido. El reverso, en cambio, se estructura de una forma similar a la cartilla, dividiendo la hoja en tres partes. A la izquierda aparece un estudio antropométrico de cuatro cabezas copiado de De varia commensuracion de Arfe, a la derecha, en lugar de los aforismos, el dibujo del rostro de un jesuita que eleva su mirada al cielo y en la parte inferior y de forma apaisada, la zona reservada para ubicar el texto explicativo. ${ }^{32}$ En este texto el autor cita el tratado de simetría de Juan de Arfe. Este hecho, junto estos dibujos antropométricos y la voluntad manifestada por el autor en las hojas anteriores de dedicar una parte

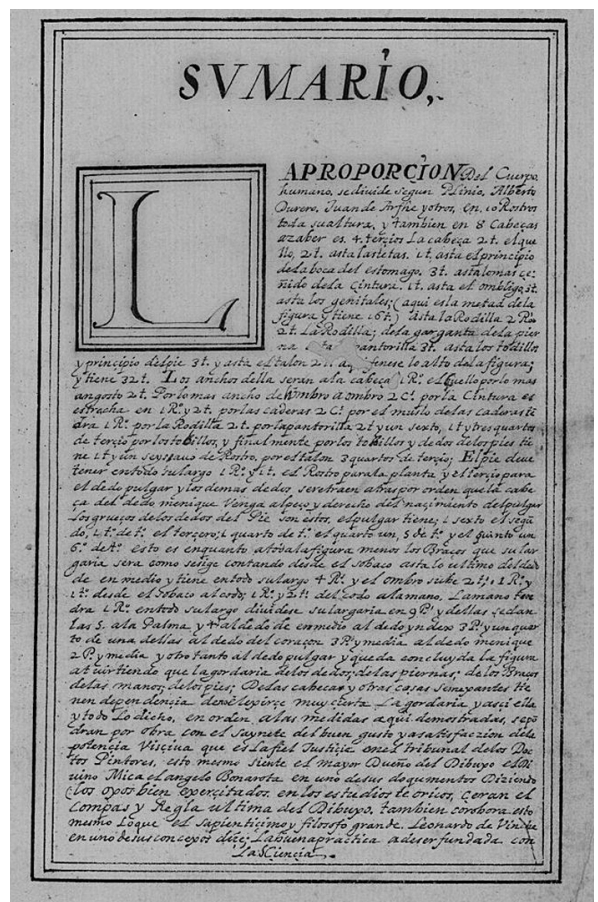

Fig. 11. Vicente Salvador Gómez, Sumario de "La Proporción", Cartilla y fundamentales reglas de pintura, Valencia 1674. Biblioteca del Palacio Real de Madrid, () Patrimonio Nacional.

de la cartilla al estudio de la simetría, podrían dar lugar a pensar que estaríamos ante el único dibujo preparatorio destinado a esta sección que se conserva (Fig. 12).

También se encuentra en el Museo del Prado un dibujo a pluma de la Inmaculada Concepción fir-

31 SVMARIO LA PROPORÇIÓN del cuerpo humano se diuide, según Plinio, Alberto Durero, / Juan de Arfhe y otros, en 10 rostros toda su altura y también en ocho cabeças, / a zaber: es 4 terçios la cabeza, 2 terçios el que-/llo, 2 terçios asta las tetas, 1 terçio asta el principio / de la boca del estómago, 3 terçios asta lo más çe-/ñido de la çintura, 1 terçio hasta el ombligo, 3 terçios / asta los genitales (aquí es la metad de la / figura y tiene 16 terçios). Asta la rodilla 2 Ros, / 2 t terçios la rodilla; de la garganta de la pier-/na [as]ta la pantorrilla 3 terçios; asta los todillos / y prinçipio del pie 3 terçios; y asta el talón 2 [terçios] A[quí] fenese lo alto de la figura / y tiene 32 terçios. Los anchos della serán a la cabeça [...]rostro. El cuello por lo más / angosto 2 terçios; por lo más ancho, de hombro a ombro, 2 Cs. Por la cintura es / estrecha en 1 rostro y 2 terçios por las caderas 2 Cs Por el muslo de las caderas ten-/drá 1 rostro Por la rodilla 2 terçios por las pantorrilla 2 terçios y un sexto, 2 terçios y 3 quartos I de terçio por los tobillos y finalmente por los tobillos y los dedos de los pies tie-/ne 1 terçio y un seyssauo de rostro. Por el talón 3 quartos de terçio. El pie deue / tener en todo su largo 1 rostro y 1 terçio. El rostro para la planta y el terçio para / el dedo pulgar; y los demás dedos se retraen atrás por orden que la cabe-/ça del dedo meñique venga al peço y derecho del naçimiento del pulgar. / Los gruesos de los dedos del pie son éstos: el pulgar tiene 1 sexto; el segun-/do 2 terçios de terçio; el tercero 1 quarto de terçio; el cuarto un quinto de terçio; y el quinto 1 / sesto de terçio. Esto es en quanto a toda la figura, menos los braços, que su lar-/gura será como se sige. Contando desde el sobaco asta lo último del dedo / de en medio y tiene en todo su largo 4 rostros, y el hombro sube 2 terçios, 1 rostro y / 2 terçios desde el sobaco al codo, 1 rostro y 2 terçios del codo a la mano. La mano ten-/drá 1 rostro en todo su largo. Diuídese su largura en 9 partes y dellas se dan / las 5 a la palma y 4 al dedo de en medio, al dedo yndex 3 partes, y un quar-/to de una dellas al dedo del coraçón. 3 R. y media al dedo menique; / 2 partes y media y otro tanto al dedo pulgar. Y queda concluyda la figura, / atuirtiendo que la gordaria de los dedos, de las piernas, de los braços, / de las manos, de los pies, de las cabecas y otras cosas semexantes tie-/nen dependençia de no elexirçe muy çierta la gordaria, y asçí ella / y todo lo dicho en orden a las medidas aquí demostradas se pon-/drán por obra con el saynete del buen gusto y a satisfazión de la / potencia visçiua, que es la fiel justiçia en el tribunal de los doc-/tos pintores. Esto mesmo siente el mayor dueño del dibuxo, el di-/uino Micaelángelo Bonarota, en uno de sus doqumentos diziendo: / "los oxos bien exerçitados en los estudios teóricos çerán el / compás y regla última del dibuxo". También corobora esto / mesmo lo que el sapientíçimo y filósofo grande Leonardo de Vinche / en uno de sus concexos diçe: "La buena práctica a de ser fundada con / la sçiençia".

32 ANGULO ÍNIIGUEZ, Diego y PÉREZ SÁNCHEZ, Alfonso Emilio, 1988, pp. 78 y láminas 399 y 400. 


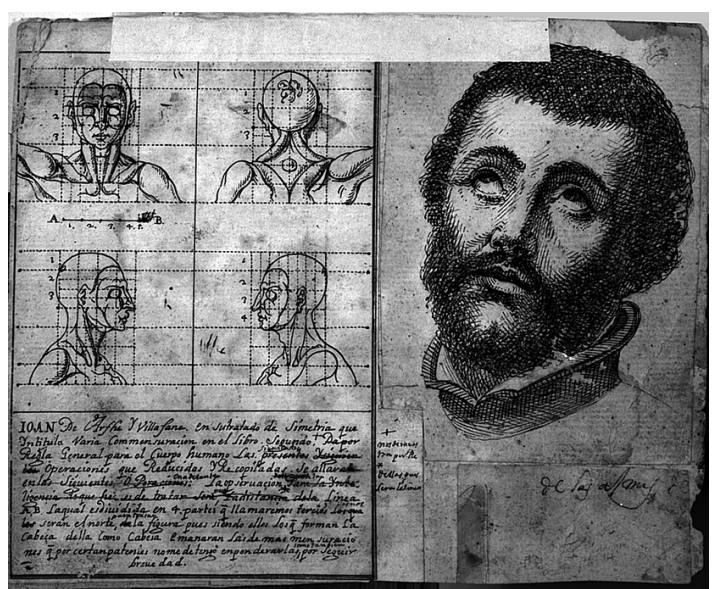

Fig. 12. Vicente Salvador Gómez, Dibujos antropométricos, Valencia 1674. Museo del Prado, Madrid. (c) Archivo fotográfico Museo Nacional del Prado.

mada por Vicente Salvador Gómez. El hecho de que tenga las mismas medidas y esté fechada en 1674, el mismo año que la portada de la cartilla, podría indicar que este dibujo podría corresponderse con la tercera página de la cartilla, la siguiente a la dedicatoria realizada a la Virgen María. Aunque la página ha sido cortada y el número no aparece en el extremo superior derecho, las medidas del borde que enmarca el dibujo es el mismo que el resto de las páginas, es decir, 20 por $13 \mathrm{~cm}$. La clave de esta página, publicada y citada por Sánchez Cantón en Dibujos Españoles y en Fuentes Literarias, se remonta al hecho de que en un catálogo perteneciente a la colección de dibujos españoles del francés Paul Lefort, que fue adquirida por éste a Ceán Bermúdez, se describe como un dibujo "arrancado" de un manuscrito escrito por Vicente Salvador Gómez sobre el arte de dibujar (Fig. 13).

Acerca de la proveniencia y circulación de esta cartilla y con los datos de que disponemos, nos atrevemos a realizar la siguiente hipótesis. Teniendo en cuenta el perfecto estado de conservación de la cartilla y la ausencia de manchas, arrugas o desperfectos en el papel, ésta apenas habría sido utilizada como herramienta de taller. Probablemente fue adquirida por Ceán Bermúdez, antes de 1800, cuando estudiaba la vida de Vicente Salvador para incluirlo en su Diccionario ${ }^{33}$ y a continuación integraría la colección de dibujos y grabados que vendió en París a Lefort. Éste último, valorando más el documento como un dibujo que como una herramienta didáctica, vendería por se-

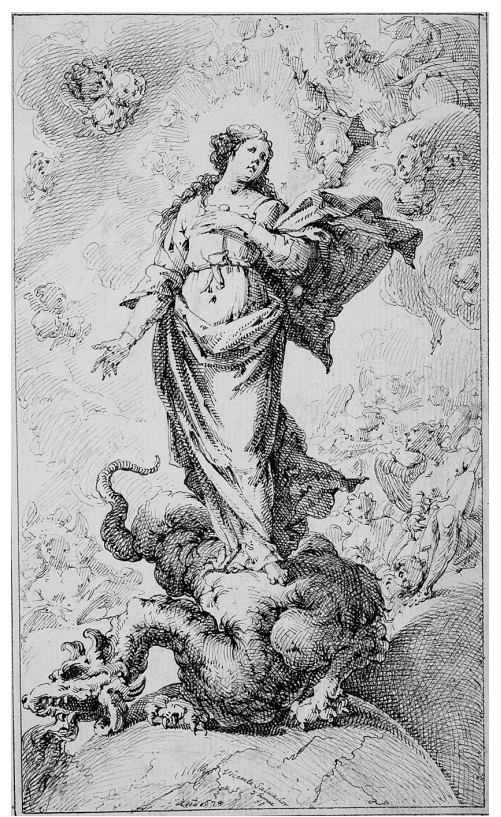

Fig. 13. Vicente Salvador Gómez, Immaculada Concepción, Valencia 1674. Museo del Prado, Madrid. (c) Archivo fotográfico Museo Nacional del Prado.

parado el dibujo de la Virgen Inmaculada del resto de la cartilla, que sería adquirida por Manuel Ramón Zarco del Valle, quien precisamente durante esos años vivía también en París. Respecto al resto de las hojas de la cartilla, Sánchez Cantón, ${ }^{34}$ recoge que fue encontrado por su amigo, el jefe de la Biblioteca de Palacio Real, Jesús Domínguez Palacio quien manifestó tener motivos para sospechar que fue regalada por Zarco del Valle a la biblioteca, de la que fue bibliotecario mayor desde 1875 hasta 1893.

\section{La fisiognomía en la pintura de Vicente Salvador Gómez}

Analizando las pinturas de Vicente Salvador, la mayor parte de tema religioso, se constata el uso de estos modelos fisiognómicos. El pintor, como gran retratista, capta de forma extraordinaria los rasgos físicos de los modelos en su estado natural y las emociones y pasiones sentidas gracias a sus expresiones. Vicente Salvador sabía personificar todos los estados del alma desde la serena dignidad de una venerable mártir, la templada devoción de un santo ante la imagen de la Virgen a la gran vitalidad de los protagonistas de sus fábulas. En estos modelos, pero también en otros más estereotipados, recoge la tradición fisiognómica,

33 CEÁN BERMÚDEZ, Juan Agustín, 1800, ed. 2001.

34 SÁNCHEZ CANTÓN, Francisco Javier, 1934, III, p. 87. 
ofreciendo por lo general, unos rasgos bien proporcionados que se corresponden con los rostros de los nobles de corazón y que son los que describe minuciosamente en su cartilla de dibujo..$^{35}$

Para la personificación de individuos con buenos sentimientos, el pintor utiliza rostros modelados de forma ovalada, con frentes despejadas, ojos hermosos y almendrados, tabique nasal pronunciado, nariz prominente y pequeñas bocas con labios carnosos, mientras que las manos suelen tener las falanges de los dedos muy estilizados. En cuanto a la representación de los modelos femeninos, sus vírgenes y santas, suelen mostrar una tez nacarada, los párpados ligeramente sombreados y las mejillas sonrosadas, mostrando cierto aire de melancolía y un gesto elocuente

La confirmación del uso del repertorio de tipos humanos que ofrece en la Cartilla como modelos para obras concretas, se encuentra en el dibujo preparatorio de la cabeza de San Francisco Javier. Este dibujo, que se encuentra en la única hoja conservada en la parte dedicada a la simetría, coincide exactamente con la cabeza de San Francisco Javier, como Doctor en Teología del Museo de Bellas Artes de Valencia. Es la cabeza de un santo que muestra los rasgos característicos de los personajes piadosos, con profundos principios cristianos, recogidos en la Cartilla. San Francisco Javier eleva melancólicamente su rostro ovalado, en el que destaca unos profundos ojos almendrados hacia la visión divina, conformándose así como un documento de excepcional interés que revela el uso práctico de esta cartilla en su propio taller $^{36}$ (Figs. 12 y 14).

Estas teorías fisiognómicas, aunque fuertemente censuradas, resultaron muy útiles para la iglesia de la contrarreforma y su uso fue algo común en la pintura y en la literatura artística del siglo XVII español. La representación de la expresión de las pasiones en las artes visuales de la España del siglo XVII debe ser entendida en el contexto de la

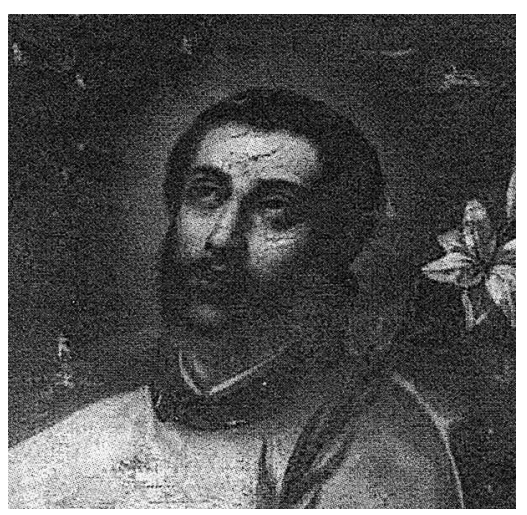

Fig. 14. Vicente Salvador Gómez, San Francisco Javier, Valencia 1674. Museo de Bellas Artes, Valencia.

herencia de las directrices tridentinas, de las que emanaba un nuevo concepto del arte y una nueva justificación para las imágenes devocionales cristianas que, desde finales del 1600, debían dar respuesta a las dos grandes preocupaciones de la iglesia, la protección y la propaganda de la fe. ${ }^{37} \mathrm{~A}$ lo largo del siglo XVII la literatura artística española se había hecho eco de las teorías de Paleotti, Molano, Borromeo y otros ${ }^{38}$ y sus máximos exponentes, Vicente Carducho, Jusepe Martínez y Francisco Pacheco, aunque en distinto grado, las incluyeron en sus obras. Pacheco, por ejemplo, ya desde la misma definición de la pintura expone que ésta debe mostrar las pasiones del ánimo. Según sus palabras: "La pintura era arte que imitaba con líneas y colores los efectos de la naturaleza, del arte y de la imaginación, (...) y muestre a nuestros ojos los efectos y pasiones del ánimo". ${ }^{39}$ Las teorías de los afectos, desarrolladas en el segundo libro de la Retórica de Aristóteles era la base de este pensamiento. En ellas se establecía la técnica de la argumentación en la que se configura la representación como un discurso expresivo y articulado según el método de la persuasión ${ }^{40}$ y las imágenes de las experiencias interiores hallaron de este modo su necesario soporte teórico. ${ }^{41}$

\footnotetext{
${ }^{35}$ El catálogo completo de sus obras, que ronda las cuarenta pinturas localizadas y documentadas, nueve atribuidas y cerca de sesenta que han desaparecido o no se encuentran localizadas, pero han sido citadas en otros documentos, puede encontrarse en MARCO GARCÍA, Víctor, 2006, la mayoría de las cuáles se encuentra en el Museo de Bellas Artes de Valencia.

36 El estudio de la cabeza de San Francisco Javier fue puesta en relación con la cartilla de Vicente Salvador por ESPINÓS DíAZ, Adela, 1994, pp. 170-171 y MARCO GARCÍA, Víctor, 2006, p. 172.

37 MAHON, Denis, 1937; ZERI, Federico, 1957; PRODI, Paolo, 1962, pp. 123-212 y LECOAT, Gerard, $1972, n^{\circ} 2$.

38 MOLANUS, Johannes, 1570; PALEOTTI, Gabriele, 1582; MOFFITT, John F., 1987, pp. 295-306.

39 PACHECO, Francisco, 1649, p. 78.

40 ARGAN, Giulio Carlo, 1970, pp. 167-176.

41 FUMAROLI, Marc, 2003, p.186. En el caso de Carducho, se ofrece toda una galería de distintos caracteres o emociones interiores que iban desde el justo o el prudente al lujurioso o al melancólico.
} 
En estas teorías de los afectos los lectores encontraban los preceptos de los dos aspectos que conforman la base de estas teorías, la fisiognomía y la expresión de las pasiones. ${ }^{42}$ La diferencia entre ambas era recogida, entre otros, por Carducho en su diálogo octavo, dedicado en parte a la fisiognomía. Así divide los movimientos del alma en dos grupos, el primero que se ocupa de los "movimientos, acciones, facciones y colores de los hombres viciosos y de los hombres virtuosos por su naturaleza e inclinación propia", es decir aquellos rasgos del carácter propio e inmutable a cada ser humano y en segundo lugar de aquellos que "se introduzen (sic) y pegan al hombre por accidentes" por lo tanto, emociones de carácter espontáneo y transitorio. Carducho dedicó el octavo de sus Diálogos a este tema, situando a la fisionomía a la altura de la perspectiva, de la anatomía o de la geometría y Pacheco, aunque no le dedica ningún capítulo de forma específica, defiende su uso a lo largo de todo su tratado. En la definición de la pintura, y siguiendo el texto de Lomazzo, el suegro de Velázquez asegura que la pintura debe mostrar las pasiones del ánimo, pero esta afirmación no va a quedar aislada en esta cita ya que, en la parte correspondiente a los movimientos corporales y en el de los afectos y pasiones del ánimo, traduce literalmente las teorías sobre la representación de las emociones y sobre la fisiognomía del propio Lomazzo. En definitiva, ejemplos todos ellos de la indiscutible presencia de estas teorías, de forma práctica, pero también teórica, en los talleres artísticos del siglo XVII español.

\section{Fuentes artísticas y literarias de la Cartilla}

En un alarde de vanidad para algunos y en un ejercicio de honradez académica para otros, ${ }^{43} \mathrm{Vi}$ cente Salvador nombra en su Introducción los tratados artísticos a los que ha recurrido como fuen- tes de carácter general para la composición de la cartilla. Afirma que ha consultado Las vidas de Vasari, el Trattato dell'arte della pittura, scoltura et architettura de Lomazzo, De' veri precetti della pittura de Armenini, los Diálogos de la pintura de Carducho, El arte de la pintura de Pacheco, De varia commensuracion de Arfe y Villafañe, Della simmetria de Durero y algún texto de Leonardo da Vinci. ${ }^{44}$ Además de éstos y ya en las hojas dedicadas a la fisiognomía, el autor cita entre sus fuentes, principalmente De anima de Aristóteles para los aforismos fisiognómicos, y se apoya de forma más amplia en San Isidoro, Aristóteles, Escoto, Philemon y Della Porta.

De entre ellos, y una vez analizada la cartilla, tenemos constancia de que ha leído el tratado de Carducho, ya que sigue el mismo orden clásico a la hora de ordenar los temas a tratar en la cartilla, además que lo cita directamente para reforzar la importancia de la actividad tenaz del dibujo entre los alumnos. Así como a Juan de Arfe y Villafañe y a Alberto Durero, porque directamente ha copiado sus cabezas esquemáticas. Sin embargo, sí está meridianamente claro que estas fuentes han sido utilizadas, no lo está tanto con respecto a las fuentes que manifiesta haber utilizado para sus aforismos fisiognómicos. El autor cita directamente a Aristóteles y su obra De anima, como el texto que ha seguido, pero ninguna de las sentencias que él atribuye al filósofo griego se encuentran en su obra. En De anima, Aristóteles otorga un papel fundamental a los ojos, equiparándolos con el alma cuando afirma "En efecto, si el ojo fuera un animal, su alma sería la vista: ésta es, desde luego, la entidad definitoria del ojo", ${ }^{45}$ pero no enuncia los aforismos citados en la cartilla. ${ }^{46}$

En cuanto a la obra Fisiognomía de Pseudo-Aristóteles, sí es un texto dedicado íntegramente a esta

42 Para la retórica de los afectos en el canto, vid. DÍAZ MARROQUín, Lucía, 2008.

${ }^{43}$ El primer extracto de la cartilla fue publicado por Sánchez Cantón en 1934. En aquella ocasión, afirmó que Vicente Salvador Gómez carecía de estudios ya que usaba numerosos vulgarismos y lo calificaba de "humilde artista de corta lectura". SÁNCHEZ CANTÓN, Francisco Javier, 1934, vol. III, pp. 88 y 91.

44 VASARI, Giorgio, 1568; LOMAZZO, Giovanni Paolo, 1584; ARMENINI, Giovanni Battista, 1587; CARDUCHO, Vicente, 1633; PACHECO, Francisco, 1649; ARFE Y VILLAFAÑE, Juan, 1585 (ed.), 1974. La edición más habitual del tratado de Durero en la España del siglo XVIII fue la traducción realizada por Gallucci Salodiano al italiano, DURERO, Alberto, 1591. Respecto a Leonardo, probablemente se trate de la edición francesa del tratado de pintura, Traitté de la peinture, publicado en París, en 1651 y que esto haya motivado que se refiera a él como "Leonardo de Vinche, francés".

${ }^{45}$ Aristóteles, Acerca del alma, 2.1.412b.15-20.

${ }^{46}$ No obstante, y aunque Aristóteles no tiene un tratado sobre fisiognomía es un tema recurrente en sus obras. Encontramos ejemplos de ello en Historia de los animales I 488b 12, donde destaca las diferencias fundamentales entre el carácter de los distintos animales, otorgando a cada raza animal un carácter particular. En Sobre la generación de los animales $769 \mathrm{~b} 18$ y ss. Aristóteles pone como el ejemplo un episodio en el que "un fisiognomista reducía todos los tipos de expresiones a las de dos o tres animales logrando a menudo convencer a su público de la verdad de sus afirmaciones" aunque es en los Analíticos primeros II 70b y ss. donde Aristóteles ofrece la justificación teórica de la disciplina fisiognómica. 
materia y parecería que algunas de sus sentencias podían haberse inspirado en sus teorías, como por ejemplo que las orejas "grandes y pandas es señal de rudo ingenio, perezoso o fardón", que la cabeza "grande y redonda de toda parte es señal de ser hombre secreto, sagaz, ingenioso, discreto, de gran imaginación o leal" o que el que tiene la cabeza pequeña es "de poco juicio, imprudente y flaco de corazón". ${ }^{47}$ Pero hay otras sentencias que, aunque podrían haberse inspirado en Pseudo-Aristóteles, se corresponden más exactamente con otra obra que también tuvo una enorme difusión en los ambientes médicos, filosóficos, astrológicos y mánticos desde finales del siglo XIII, la obra de Miguel Escoto Liber phisionomiae.

Como es sabido, entre las ocupaciones del médico, astrólogo y alquimista medieval Miguel Escoto, también tenía su hueco la de traductor y escritor. De entre las obras que publicó, su obra principal es el Liber introductorius, dividido en tres libros, el Liber quatuor distinctionem, el Liber particularis y el Liber phisionomiae. ${ }^{48} \mathrm{Y}$ es precisamente esta última, la parte quizás más difundida de su obra, la que parece podría haber servido de inspiración para los textos fisiognómicos de Vicente Salvador.

La cartilla de Vicente Salvador sigue el mismo orden que el texto de Escoto comenzando por la parte superior del cuerpo humano y describiéndolo de forma descendente, no como Pseudo-Aristóteles en Fisiognomía que lo hace a la inversa, en sentido ascendente. Escoto parte del cabello, siguiendo por la frente, las cejas, el entrecejo, ojos, nariz, orejas, labios, dientes, etc... hasta llegar al conjunto de la cabeza, para continuar con el cueIlo hasta los pies. Vicente Salvador copia esta direccionalidad descendente aunque, quizás y debido a su vocación de síntesis, se ocupó tan solo de los rasgos principales, partiendo directamente de los ojos y a continuación siguiendo con narices, boca, orejas y cabeza. Además de esto, se observa que Vicente Salvador, alejándose de otros autores, como el mismo Aristóteles, sigue el mismo estilo de composición literaria que Escoto para su obra. Una exposición sistemática y ordenada que de forma breve y sucinta enuncia las descripciones fisiognómicas a modo de sentencia, en lugar de largos párrafos descriptivos. Esto, además de conseguir un mayor grado de concreción, potenciaría su vertiente didáctica y su grado de inmediatez.
Por último y quizás más importante, se observa que las descripciones coinciden en numerosas ocasiones en ambos autores. Aunque Vicente Salvador escoge unas frases más concisas y resumidas, a veces incluso llega a la copia casi literal. Por ejemplo, Vicente Salvador afirma que aquellos que tienen los ojos hundidos "denotan al hombre astuto, engañoso, de ánimo dañado y muy malicioso", siguiendo las afirmaciones de Escoto de que "naturalmente ven mucho y penetran con la vista, pero suelen ser sospechosos, maliciosos, traidores (...)" ambos comienzan exponiendo diferentes tipos de ojos cuyas cualidades son el tamaño o la forma fuera de lo común (muy grandes, muy pequeños, saltones, hundidos,...) y también ambos cierran el capítulo describiendo los ojos medianos de los que Vicente Salvador afirma "denotan ingenio y buenas costumbres, majestad, prudencia y discusión con liberalidad" y Escoto "son mansos, leales y verdaderos, tienen buen ingenio y gran intelecto".

Este gran parecido entre ambos textos se observa para muchos de los rasgos del cuerpo, también hablando de las cabezas grandes y redondas, Salvador afirma que es señal de ser "secreto, sagaz, ingenioso, discreto y de gran imaginación como muy leal" y Escoto "secreto, astuto, ingenioso, discreto, de gran imaginación, trabajoso, constante y leal" y así a lo largo de la cartilla en numerosos ejemplos.

Llegados a este punto, hay que recordar la afirmación taxativa de Vicente Salvador de que los aforismos fisiognómicos los ha tomado de la obra De anima de Aristóteles. Ante la imposibilidad de encontrar estos aforismos en parte alguna de la obra de Aristóteles, habría que plantearse otra solución. Una posible hipótesis se basaría en el desconocimiento por parte del pintor valenciano de las obras del filósofo griego o un interés de querer ocultar a Escoto como fuente de sus teorías. No hay que olvidar que éste último había sido acusado de nigromante y el pintor valenciano ostentaba el cargo de Censor de Imágenes del Santo Oficio de la Inquisición. Pero esta solución no parece tener consistencia ya que él mismo cita a Escoto en su cartilla, junto con San Isidoro, Polemón, Della Porta y Aristóteles.

Otra hipótesis se basaría en que el texto que inspira a Vicente Salvador sea un ejemplar de la obra

\footnotetext{
47 Según Aristóteles las orejas grandes son propias de los asnos, "los que tienen la cabeza grande son inteligentes" en cambio, los que la tienen pequeña "no tienen capacidad de percepción". PSEUDO-ARISTÓTELES (ed.), 1999, pp. 69.

48 THORNDIKE, Lynn, 1965.
} 
sobre fisiognomía de Miguel Escoto, que estuviese unido a su traducción del Comentario realizado por Averroes de De anima de Aristóteles. ${ }^{49}$ Este hipotético error en cuanto a la diferenciación entre ambas obras, el Liber phisionomiae de Escoto y la traducción de Aristóteles, explicaría la confusión en cuanto a su autoría y justificaría que tomase por obra de Aristóteles aquellos enunciados fisiognómicos que corresponderían a Escoto, aunque esto tampoco se puede afirmar ya que no se ha encontrado ningún ejemplar que cumpla estos extremos

Por último, se plantea una última hipótesis y es que el texto utilizado por Vicente Salvador fuese otro, el de un escritor valenciano, Fisonomía y varios secretos de naturaleza de Jerónimo Cortés..$^{50}$ La posibilidad de que ésta sea la fuente para la cartilla se basa en que gran parte del tratado del valenciano es una copia directa del de Escoto. Aunque en la introducción se cita directamente a Tisuerio, Escoto y Pedro de Ribas como "los autores de quienes se ha sacado todo lo que contiene" y a falta de conocer el texto de Tisuerio ${ }^{51}$ del que no se tiene noticia, se puede afirmar que el tratado es casi una traducción del de Escoto.

Aún así, y aunque esta hipótesis parezca la más acertada, por la cercanía tanto física como temporal entre ambos escritores presenta el inconveniente de que Vicente Salvador cita textualmente el nombre de Escoto y no el de Jerónimo Cortés.

De cualquier modo, lo que sí parece demostrado es que Vicente Salvador, Censor de Imágenes del Santo Oficio de la Inquisición utiliza como fuente para su cartilla el tratado de Miguel Escoto, de forma directa o a través de la obra de Jerónimo Cortés. Este texto, como cualquier otro relacionados con materias deterministas asociadas a la mántica, se encontraban en el Índice de libros prohibidos de 1640. Por ello, el pintor, además de correr el riesgo de ser enjuiciado por el delito de posesión de libros prohibidos, manifestaba una enorme contradicción personal. Ello, no obstante y aunque pueda parecer una incoherencia, habría de ser entendido como una licencia de vocación humanística, encaminada a saciar el apetito de conocimiento que manifiesta el pintor a lo largo de los años que dirige la academia de dibujo. ${ }^{52}$

Respecto a otra de las fuentes a las que recurre, el texto de Della Porta y su presencia en el ámbito artístico español del siglo XVII, se pueden citar las palabras de Julián Gállego cuando afirma "Ni en la Biblioteca de Velázquez, ni en ninguna de hombre culto y de pintor erudito, puede faltar la Fisiognomía de Della Porta, donde la belleza o fealdad de un rostro humano, por su semejanza con los animales, denuncia las cualidades del alma". Estas palabras enunciadas en Visión y símbolos en la pintura española del siglo de oro resumen a la perfección la situación del principal tratado sobre fisiognomía que circulaba por Europa, incluida España, durante el siglo XVII..$^{53}$ El texto de Della Porta era el único tratado de fisiognomía publicado hasta el momento que ilustraba sus teorías con una completísima colección de grabados, lo que le confería un logrado valor didáctico y una gran utilidad, concretando visualmente los rasgos de cada carácter o temperamento. ${ }^{54}$ Fisiognomía fue, sin lugar a dudas, el libro de referencia para estudiosos de diversos campos entre los que se inclu-

\footnotetext{
${ }^{49}$ Hemos de recordar que el Liber phisionomiae a menudo lo hayamos titulado De secretis naturae, aunque solo una parte de la obra esté dedicada a la fisiognomía THORNDIKE, Lynn, 1923, vol. II, p. 328; FOERSTER, Richard, 1893, vol. I, pp. XXIIIXXVI. Como texto latino se ha utilizado el ejemplar de la Bibliothèque Nationale de France que se encuentra en Gallica (http://gallica.bnf.fr/ark:/12148/bpt6k585489/f3.chemindefer). Se cita por página, tal y como aparecen numeradas ahí. En relación con aquellos que tienen los ojos hundidos Vicente Salvador enuncia: "Los que los tienen hundidos son perversos; Escoto: "Los ojos muy hundidos y entrados denotan hombre astuto, engañoso, de ánimo dañado y muy malicioso"; y Jerónimo Cortés "Los que tienen los ojos muy hondos y casi escondidos (...) significan ser el hombre sospechoso, malicioso, de gran ira, de malas costumbres, muy memorioso, osado, cruel, mintroso de ligero, amenazador, vicioso, lujurioso, superbo, ínvido y engañador y burlador".

50 Jerónimo Cortés compuso varias obras relacionadas con la ciencia como Lunario y Pronóstico perpetuo (1594), Aritmética (1604), Libro de secretos (1610), Historia de los animales (1613), aunque la obra que interesa es Fisonomía, y varios secretos de naturaleza (1597).

${ }^{51}$ Caro Baroja sugiere que debe tratarse de un error en el nombre y que en realidad se trataría de Jean Taisnier, tutor de los pajes de Carlos V. Este autor escribió un libro sobre quiromancia y posiblemente paglió el trabajo de Cocles sobre fisiognomía. CARO BAROJA, Julio, 1988, p. 177.

52 Apoyando la teoría de que los textos de Escoto sobre fisiognomía gozaron de una gran popularidad en el ambiente cultural y cosmopolita de la Valencia de los siglos XVI y XVII, hay que subrayar que Jerónimo Cortés va a componer en 1557 su Fisonomía y varios secretos de naturaleza, texto prácticamente copiado del de Escoto.

${ }^{33}$ GÁLLEGO, Julián, 1987, p. 194

${ }^{54}$ CARO BAROJA, Julio, 1988 y DELGADO MARTíNEZ, Natalia, 2002, pp. 205-229.
} 
yeron pronto los artistas que apoyaban la teoría que calificaba a la fisiognomía como una materia "necesaria para la pintura científica", y éste era el caso de Vicente Salvador. ${ }^{55}$ El autor de la cartilla elige los rasgos físicos del león para ilustrar sus ejemplos de cabezas. Un animal al que se le atribuía la naturaleza valiente y se relacionaba con los hombres de bien y héroes de forma tradicional desde la antigüedad. Además, la descripción que hace Della Porta del hombre magnánimo está directamente inspirada de la realizada por PseudoAristóteles. En ella se ofrecen los mismos rasgos físicos y con respecto a su faceta espiritual añade: "en lo anímico es liberal y generoso, magnánimo y deseoso de vencer, manso, bueno y cariñoso con quienes tiene trato". ${ }^{56}$ El león siempre ha encarnado el tipo masculino perfecto, depositario tanto de las más altas virtudes morales como de las físicas por lo que muchos artistas lo han utilizado como modelo para extrapolar sus virtudes con las del personaje representado quizás por ello Vicente Salvador, siguiendo en la misma línea que el resto de la cartilla, lo escoge como modelo de los caracteres más justos. ${ }^{57}$

\section{La biblioteca de Vicente Salvador Gómez}

Una vez estudiadas las fuentes de la cartilla y analizados los textos que le sirvieron de inspiración, es de una enorme e inusual fortuna poder acce- der al inventario testamentario de la biblioteca de Vicente Salvador y poder así contrastar los títulos de las obras que contribuyeron a su formación y que le sirvieron para componer su trabajo. ${ }^{58}$

Actualmente se puede confirmar que, la amplísima cultura del autor, que fue puesta en duda por Sánchez Cantón, tiene su origen en una envidiable colección de cuatrocientos diez volúmenes. Un número altísimo para la época si tenemos en cuenta que entre los pintores y grandes coleccionistas se puede citar el caso de Vicente Carducho, con una biblioteca de trescientos siete libros o Diego Velázquez con ciento cincuenta y seis libros. $^{59}$ Entre los inventariados en el testamento de Vicente Salvador, veintiocho estarían dedicados al arte, la arquitectura, la geometría y los emblemas; diez a la mitología e historia; ocho serían libros religiosos; doce de literatura y cinco de filosofía. A lo que habría que sumar una colección de seiscientas estampas de diversos temas.

El origen de esta riquísima biblioteca radica en el excepcional afán de conocimiento de su propietario, que durante toda su vida fue adquiriendo volúmenes que circulaban en un enclave geográfico excepcional, como es Valencia, pero también porque parte de ellos fueron adquiridos a Alonso Cano en marzo de 1673. En aquel año Vicente Salvador realizó la compra de los libros que éste había

\footnotetext{
${ }^{55}$ Se tiene constancia de que el tratado de Della Porta estaba presente en dos de las bibliotecas de artistas españoles, en concreto en la de Velázquez y la de Carducho. Vicente Carducho recomendaba la lectura del texto de Della Porta en sus Diálogos de la Pintura, por lo que no resulta sorprendente que se haya registrado un ejemplar en el inventario de sus bienes. En ambos casos la edición que tenían era la latina de 1601 que era la más completa e incluía grabados para ilustrar sus teorías, convirtiendo de este modo el tratado teórico en un manual de gran didactismo y mucho más práctico. Para la presencia de los textos de fisiognomía en las bibliotecas de artistas del siglo XVII vid. ALBERO MUÑOZ, María del Mar, 2011, pp. 37-51.

${ }^{56}$ La descripción que ofrece Pseudo-Aristóteles es la siguiente: "Siendo eso así, parece que de todos los animales el león es el que ha adoptado los rasgos más perfectos del tipo masculino. Pues su boca es de tamaño considerable, su rostro bastante cuadrangular, no excesivamente óseo, la mandíbula superior no sobresale sino que está equilibrada con la inferior, la nariz más gruesa que fina, los ojos castaños claros y huecos, ni redondos en exceso ni demasiado oblongos, el tamaño proporcionado, la ceja considerable, la frente cuadrangular y algo hundida desde el medio, pero prominente cual una nube en dirección a las cejas y a la nariz, por debajo de la frente. Desde encima de la frente tiene las melenas dobladas como si fuese un penacho, la cabeza simétrica, el cuello muy largo y proporcionado con su gordura, con melenas pardas, ni erizadas ni excesivamente torneadas, la zona de las clavículas más bien suelta que apretada, los hombros robustos, el pecho fuerte, la parte superior de la espalda ancha y los costados y espaldas poderosos, como conviene. Las caderas y muslos de este animal son bastante magros, sus piernas fuertes y robustas, el paso decidido y todo el cuerpo articulado y vigoroso, ni demasiado duro ni húmedo en exceso. Camina pesadamente, anda a grandes zancadas y estremece con fuerza sus hombros cuando avanza". PSEUDOARISTÓTELES (ed.), 1999, pp. 59-60.

57 Del texto de Della Porta existen varias versiones, las más importantes son DELLA PORTA, Giambattista, 1627 (seis libros), ed.1990; DELLA PORTA, Giambattista, 1586 (cuatro libros); DELLA PORTA, Giambattista, 1610 (seis libros) (ed.), 1971 y DELLA PORTA, G.B. Fisiognomía. Ed. MANJARRÉS GONZÁLEZ, Miguel Ángel, 2007. DELLA PORTA, Giambattista, 1627 (ed.), 1990, pp. 184-185. TORRINI, Maurizio et al., 1990. El ejemplo del león ha sido un tema recurrente para artistas de todos los tiempos. Es el caso de Leonardo y algunos de sus dibujos, como el del Viejo con la guirnalda de hiedra y cabeza de león o los apuntes realizados por Rubens, cuando ilustra su Teoría de la figura humana. ROSAND, David, 1969, p. 35.

58 Para la publicación del testamento de Vicente Salvador Gómez y su estudio vid. SALORT PONS, Salvador; LÓPEZ AZORÍN, $M^{a}$ José y NAVARRETE PRIETO, Benito, 2001, pp. 393-424.

59 CALVO SERRALLER, Francisco, 1979, pp. XX-XXV; SÁNCHEZ CANTÓN, Francisco Javier, 1925, Vol. 3, pp. 379-406; SÁNCHEZ CANTÓN, Francisco Javier, 1960, (1), Vol. 1, pp. 640-648; SÁNCHEZ CANTÓN, Francisco Javier, 1960, (2), Vol. 2, pp. 391-400.
} 
dejado en Valencia cuando tuvo que abandonar apresuradamente la ciudad para volver a Madrid, lo que contribuiría a que Vicente Salvador poseyese una colección de libros muy superior tanto en cantidad como en calidad a la de cualquier artista del siglo XVII en España.

Según consta en el acta notarial, adquirió: "Tots los modelos, papers, estampes et debuxos de diferents personajes y sacts caisex y bauls del quondam Don Alonso Cano pintor de la Magestad del Rey Phelip Quart" que habían sido enviadas por Cano desde Granada y se encontraban en la hospedería del convento mercedario de la ciudad de Valencia. Estos libros, junto con el resto de los de su propiedad, figuran en el inventario postmortem de Salvador Gómez realizado en $1678 .{ }^{60}$

Entre ellos, se encuentran los Diálogos de la pintura de Carducho, el Trattato de Lomazzo, el Euclides posteriores publicado en Roma en 1574, Discursos apologéticos de Juan de Butrón, Le vite de Vasari y De' veri precetti della pittura de Armenni. Sobre arquitectura y perspectiva tenía I quattro primi libri d'archittetura de Cattaneo, Dell'archittetura secondo $i$ precetti del Vitrubio de Rusconi, Libro apartemente all'Architettura de Labacco, De re aedificatoria de Alberti, Lo inganno deglio occhi, prospettiva pratica de Accolti, La prattica della prospettiva de Sirigatti, y Prattica della prospettiva de Barbaro, De varia commensuracion de Arfe, Arte y uso de la Architectura de Fray Lorenzo de San Nicolás, Medidas del romano de Sagredo y Noticia general para la estimación de las Artes de Gutiérrez de los Ríos.

Sobre la figura humana encontramos que, sorprendentemente tenía las dos ediciones de Durero, probablemente comprados a Cano, tanto Hierin sind begriffen vier Bucher von menschilicher Proportion, editada en alemán en Nuremberg, I quattro libri della proporzione umana la traducción italiana de Galucci y la Historia de la composición del cuerpo humano de Valverde de Hamusco. ${ }^{61}$

En cuanto a las fuentes fisiognómicas que se propone que debió consultar para la elaboración de la cartilla, en el inventario consta que poseía la
Historia general de aves y animales de Aristóteles, pero no De anima y tampoco aparece el ejemplar de Della Porta Della fisiognomia dell'huomo ni los textos de San Isidoro o Polemon. ${ }^{62}$

Por último, y respecto a la hipótesis de la utilización de la obra de Miguel Escoto o de Jerónimo Cortés como fuente fundamental para la parte relativa a la fisiognomía de su cartilla, esta idea vendría a ser corroborada por la presencia en el inventario de la biblioteca de un volumen titulado Secretos de la naturaleza (en $8^{\circ}$ ). En el trabajo de Salort, López y Navarrete se sugiere que podría tratarse del Abecedario Virginal de Excelencias del Santísimo nombre de María y propiedades naturales de piedras preciosas, aves, animales, fuentes, árboles y otros secretos de la naturaleza, Madrid, 1604, pero que, siguiendo el planteamiento establecido en el presente trabajo, desde aquí se propone que podría tratarse directamente del texto Secretos de la naturaleza de Miguel Escoto o su versión recogida en Fisonomía y varios secretos de naturaleza publicada por Jerónimo Cortés, en cualquier caso, fuente fundamental para la elaboración de la cartilla de dibujo de Vicente Salvador Gómez.

\section{Conclusiones}

Como conclusión se puede afirmar que el pintor valenciano Vicente Salvador Gómez, Académico Mayor del Aula de Dibujo de Santo Domingo de Valencia en 1670, compartiendo lo postulado por los grandes teóricos de las artes, mostró una gran preocupación por la formación de sus alumnos en la disciplina del dibujo, entendiéndolo como una herramienta básica y fundamental para alcanzar la excelencia en la pintura.

Artista con un gran afán de conocimiento, llegó a poseer la que quizás sea la biblioteca más importante conocida de un pintor del siglo XVII español, superando la cantidad de más de cuatrocientos libros y seiscientas estampas.

Ambas circunstancias motivarían que en 1674 el pintor decidiese iniciar la composición de una cartilla para la formación de sus alumnos. Su fin, esencialmente didáctico y académico fue el esta-

${ }^{60}$ NAVARRETE PRIETO, Benito, 1998, pp. 70-71, n. 261. Para el testamento de Cano, en el que declara la existencia de estos bienes y su presencia en el convento de Granada vid. WETHEY, Harold, 1953, p. 119. Archivo del Reino de Valencia, Notario Francisco Sebil, año de 1673, Protocolo 4519, folios 44v-45v. Documento publicado por NAVARRETE PRIETO, Benito, 1995, pp. 135-140.

${ }^{61}$ NAVARRETE PRIETO, Benito, y SALORT PONS, Salvador, 2002, pp. 129-151.

${ }^{62}$ Aún así, ello no debe entenderse como que no fueron de su propiedad o no fueron consultados en algún momento de su vida ya que, en el caso de Della Porta tenemos la constancia de que así fue, si no que en el momento de su muerte no se hallaban en su poder. 
blecer unas reglas que ordenasen los conocimientos básicos de simetría, perspectiva, geometría y fisiognomía para la instrucción en la pintura, disciplinas que habían sido recogidas previamente en tratados teóricos. Para su composición, siguiendo el sentido clásico que inspiraba a todo tratado artístico, Vicente Salvador estudió los principales tratados que circulaban en el panorama español y europeo, extrayendo sus fundamentos y ofreciéndolos de forma ordenada, con un lenguaje y sintaxis claros y en castellano. A ello hay que sumar su visión pedagógica al componer sus hojas de una manera sistematizada, combinando dibujos y aforismos descriptivos, a modo de ejercicios memorísticos fáciles de retener en la memoria por los jóvenes alumnos. Pero, por motivos que hoy se desconocen, quizás una gran demanda de su obra pictórica, la falta de financiación o su temprana muerte cinco años después, su publicación se vio truncada quedando la cartilla inconclusa y sin llegar a ver la imprenta.

Conocer qué partes de las cuatro inicialmente proyectadas llegaron a realizarse es hoy por hoy un ejercicio de elucubración. Pero lo que se puede afirmar es que, salvando las hojas introductorias y una dedicada a la simetría, los restos de la primera cartilla de dibujo realizada en España en el siglo XVII, cuyo original se conserva, se corresponden exactamente con la parte dedicada a las teorías fisiognómicas. El amplio conocimiento de sus fuentes se evidencia no solo en sus dibujos, sino sobre todo en sus textos inspirados en los tratados clásicos, otorgando el pintor un lugar preeminente a la fisiognomía entre las enseñanzas en las que debían ejercitarse los alumnos de academias y talleres artísticos si pretendían alcanzar la categoría de "muy ducho pintor".

\section{Bibliografía}

ALBERO MUÑOZ, María del Mar. "La fisiognomía y la expresión de las pasiones en algunas bibliotecas de artistas españoles en el siglo XVII". Cuadernos de arte de la Universidad de Granada, vol. 42, 2011, pp. 37-51.

ALBERO MUÑOZ, María del Mar. "Fisiognomía en las primeras cartillas de dibujo del siglo XVII en España". En: RODRÍGUEZ ORTEGA, Nuria y TAÍN GUZMÁN, Miguel (eds.). Teoría y literatura artística en España. Revisión historiográfica y estudios contemporáneos. Madrid: Real Academia de BBAA de San Fernando, 2016, pp. $140-165$.

ALBERTI, Romano. Origine et Progresso dell' Academia del Disegno de pittori, scultori, ed architetti di Roma: dove si contengano molti discorsi et ragionamenti appartenenti alle sudette professioni. Pavía: Pietro Bartoli, 1604.

ALLORI, Alessandro. Il primo libro de' ragionamenti delle regole del disegno d'Alessandro Allori con M. Agnolo Bronzino. En: BAROCCHI, P. (ed.). Scritti d'Arte del Cinquecento, 3 vols. Milán y Nápoles: R. Ricciardi, 1971-1977, vol 2. pp. 1941-1981.

ANGULO ÍÑIGUEZ, Diego y PÉREZ SÁNCHEZ, Alfonso Emilio. A corpus of Spanish drawings, vol. IV. Londres: Harvey Miller, 1975-1988.

ARFE Y VILLAFAÑE, Juan. De varia commensuración para la esculptura y architectura. Sevilla: Andrea Pescioni, Juan de Leon, 1585. Reed. Madrid: Ministerio de Educación y Ciencia, 1974.

ARGAN, Giulio Carlo. Studi e note dal Bramante al Canova. Roma: M. Bulzoni, 1970.

ARISTÓTELES. Acerca del alma. CALVO MARTíneZ, T. (ed.). Madrid: Gredos, 2014.

ARMENINI, Giovanni Battista. De veri precetti della pittura, Libri tre. Bolonia: Francesco Tebaldini, 1587 Reed. Turín: G. Einaudi, 1988.

BAROCCHI, Paola. Scritti d'arte del Cinquecento. Milán: G. Einaudi, 1971, vol. 2, pp. 1941-1981.

BELDA NAVARRO, Cristóbal. "Alonso Cano. Reflexiones sobre escultura". En: HENARES CUÉLLAR, I. (coord.) Alonso Cano y su época. Granada: Edit. Comares, 2002, pp. 48-50.

BELDA NAVARRO, Cristóbal. "Literatura artística y escultura". En: Actas del XV Congreso Nacional de Historia del Arte (CEHA). Modelos, intercambios y recepción artísticas (de las rutas marítimas a la navegación en red). Mallorca: Universidad de las Islas Baleares, 2008, pp. 211-222.

BOLTEN, Jaap. Method and practice: Dutch and Flemish drawing books, 1600-1750. Landau: Pfalz, 1985.

BONET CORREA, Antonio. Figuras modelos e imágenes. Madrid: Alianza Editorial, 1993.

BORDES, Juan. "Teorías de la figura humana". En: GÓMEZ MOLINA, J.J. (ed.). El dibujo, belleza, razón, orden y artificio. Zaragoza: Diputación de Zaragoza, 1992.

CACHO CASAL, Marta. Francisco Pacheco y su Libro de retratos. Sevilla: Fundación Focus-Abengoa y Madrid: Marcial Pons Historia, 2011.

CALVO SERRALLER, Francisco. "La biblioteca de Carducho". En: CARDUCHO, V. Diálogos de la pintura. Madrid, 1633, Reed. Madrid: Turner, 1979, pp. XX-XXV.

CALVO SERRALLER, Francisco. Diálogos de la pintura. Su defensa, origen, esencia, definición, modos y diferencias. Madrid, 1633. Reed. CALVO SERRALLER, F. Madrid: Turner, 1979.

CALVO SERRALLER, Francisco. Teoría de la pintura del siglo de oro. Madrid: Cátedra, 1981.

CARDUCHO, Vicente. Diálogos de la pintura, origen, esencia, definición, modos y diferencias. Madrid, 1633; CALVO SERRALLER, Francisco (ed.). Madrid: Turner, 1979.

CARO BAROJA, Julio. Historia de la Fisiognómica: el rostro y el carácter. Madrid: Istmo, 1988.

CARRACCl, Annibale. Scuola perfetta para imparare a disegnare tutto il corpo humano. Roma: P. Stefanone, 1599.

CEÁN BERMÚDEZ, Juan Agustín. Diccionario histórico de los más ilustres profesores de las bellas artes en España. Madrid: Real Academia de BBAA de San Fernando, 1800. Reed. MORÁN TURINA, M. Madrid: Akal, 2001

CORTÉS, Valeria. Anatomía, Academia y Dibujo clásico. Madrid: Cátedra, 1994.

DA VINCl, Leonardo. Traitté de la peinture. Trans. Roland Fréart de Chambray. París, 1651. Reed. París: Michel de L'Ormeraie, 1977. 
DE ORELLANA, Marcos Antonio. Biografía Pictórica Valentina. Vida de los pintores, arquitectos, escultores $y$ grabadores valencianos. Ed. SALAS, X. Madrid: ParísValencia, 1930

DELGADO MARTÍNEZ, Natalia. "Fisiognomía y expresión en la literatura artística española de los siglos XVII y XVIII". Anuario del Departamento de Historia y Teoría del Arte, 14 (2002), pp. 205-229.

DELLA PORTA, Giambattista. De Humana Physiognomonia, Sorrento, 1586, 4 libros.

DELLA PORTA, Giambattista. Della fisonomia dell'uomo. Nápoles: 1610, Ed. CICOGNANI, M. Parma: Guanda, 1971.

DELLA PORTA, Giambattista. Della Fisonomia dell'Huomo. Padua, 1627, 6 libros, ed. París: Aux amateurs de Lives, 1990.

DELLA PORTA, Giambattista. Fisiognomía. Ed. MANJARRÉS GONZÁLEZ, Miguel Ángel. Madrid: Asociación Española de Neuro Psiquiatría, 2007, 2 vol.

DESJARDINS, Lucie. Le corps parlant. Savoirs et représentation des passions au XVIle siècle. París: L'Harmattan, 2000.

DÍAZ MARROQUÍN, Lucía. La retórica de los afectos. Kassel: Reichenberger, 2008.

DURERO, Alberto. Della simmetria dei corpi humani. Libri Quattro. Nuovamente tradotti dalla lingua Latina nella Italiana, da Gio. Paolo Gallucci Salodiano. Venecia, 1591.

DURERO, Alberto. Della simmetria dei corpi humani. Libri Quattro. Nuovamente tradotti dalla lingua Latina nella Italiana, da Gio. Paolo Gallucci Salodiano. Venecia: Roberto Meitetti, 1591.

ESPINÓS DÍAZ, Adela (com.). Dibujos valencianos del siglo XVII. (Celebrado en el Museo de Bellas Artes de Valencia, 1994). Valencia: Museo de BBAA, 1994.

FIALETTI, Odoardo. De excelentis y nobilitate delineatoris libri duo. Venecia, 1611.

FIALETTI, Odoardo. Il vero modo et ordine per dissegnar le parti et membra del corpo humano. Venecia, 1608.

FOERSTER, Richard. Scriptores physiognomonici Graeci et Latini. Leipzig: In aedibus B.G. Teubneri, 1893.

FUMAROLI, Marc. "Visions et extases. Figures du ravissement". En: FUMAROLI, M. Visioni ed Estasi. Capolavori dell'arte europea tra seicento e settecento. Milán: Skira, 2003, pp. 185-190.

GÁLLEGO, Julián. Visión y símbolos en la pintura española del siglo de oro. Madrid: Cátedra, 1987.

GARCÍA HIDALGO, José. Principios para estudiar el nobilísimo arte de la pintura. Madrid, 1693.

GARCÍA MAHÍQUES, Rafael. "Vicente Salvador Gómez y la iconografía en la Casa Profesa de Valencia". Boletín del Museo e Instituto Camón Aznar. Zaragoza, 1996, LXIII, pp. 57-78.

GUERCINO, O BARBIERI, Giovan Francesco, Livre de portraiture. París, 1642.

GUTIÉRREZ PASTOR, Ismael. "Sol que da vida y prudencia de todas las habilidades: Teoría y práctica del dibujo en la España del barroco". En: ANSÓN NAVARRO, A. y CENTELLAS SALAMERO, R. Dibujo español del renacimiento a Goya; La colección de la Reina María Cristina de Borbón. Zaragoza: Diputación, 2008, pp. 37-51.

LECOAT, Gerard. "Comparative aspects of the theory of the expression in Baroque age". Eighteenth-Century Studies, vol. 5, 1972, n² 2, pp. 207-223.

LEFORT, Paul. Catalogue de la collection de dessins anciens des maitres Espagnols, Flamands, Français, Ho-
Ilandais et Italians. París: Hotel des commissaires-priseurs, 1869.

LOMAZZO, Giovanni Paolo. Trattato dell'arte della pittura di Gio. Paolo Lomazzo milanese pittore. Diuiso in sette libri. Ne' quali si contiene tutta la theorica, \& la prattica d'essa pittura. Milán, 1584.

MAHON, Denis. Studies in Seicento Art and Theory. Londres: Instituto Warburg, 1937.

MARCO GARCÍA, Víctor. El pintor Vicente Salvador Gómez (Valencia, 1637-1678). Valencia: Diputació, 2006.

MARTÍN GONZÁLEZ, Juan José. El artista en la sociedad española del siglo XVII. Madrid: Cátedra, 1984.

MARTín GONZÁLEZ, J.J. El escultor en el siglo de oro. Madrid: Real Academia de BBAA de San Fernando, 1985.

MARTínEZ, Jusepe. Discursos practicables del arte de la pintura (Madrid c. 1675), ed. M. E. Manrique Ara, Madrid: Cátedra, 2006.

MATILLA, José Manuel. "Las disciplinas en la formación del Artista". En: VEGA, Jesusa (coor.). La formación del artista. De Leonardo a Picasso. Madrid: Real Academia de BBAA de San Fernando, 1989.

MCDONALD, Mark P. Renaissance to Goya. Prints and drawings from Spain. Londres: British Museum, 2012.

MENA MARQUÉS, Manuela. Catálogo de Dibujos Españoles, XV-XVI-XVII, vol. I. Madrid: Museo del Prado, 1972.

MOFFITT, John F. "'Ut Picturae Sermones' Homiletic Reflections of Velázquez's Religious Imagery". Arte Cristiana, vol. 75 (1987), pp. 295-306.

MOLANUS, Johannes. De picturis et imaginibus sacris liber unus, tractans de vitandis circa eas abusibus, et de earundem significationibus. Lovaina, 1570.

NAVARRETE PRIETO, Benito. "Sobre Vicente Salvador Gómez y Alonso Cano: Nuevos documentos y fuentes formales". Ars Longa: cuadernos de arte, n 6, 1995, pp. 135-140.

NAVARRETE PRIETO, Benito. La pintura andaluza del siglo XVII y sus fuentes grabadas. Madrid: Fundación de apoyo a la historia del arte hispánico, 1998.

NAVARRETE PRIETO, Benito y SALORT PONS, Salvador. "El saber de un artista: fuentes formales y literarias en la obra de Alonso Cano". EN: HENARES CUÉLLAR, Ignacio, et al. Alonso Cano. Espiritualidad y Modernidad Artística. Granada: Junta de Andalucía, 2002, pp. 129-151.

NAVARRETE PRIETO, Benito. El papel del dibujo en España. Madrid: Caylus, 2006.

OCAÑA MARTínEZ, José Antonio. Principios antropométricos, anatómicos y otros métodos para la representación de la figura humana según los tratadistas de artes españoles (el siglo XVII, deudas e influencias). Tesis Doctoral, Universidad Complutense de Madrid, Madrid, 2001.

PACHECO, Francisco. Arte de la pintura, 1649; BASSEGODA I HUGAS, Bonaventura (ed.). Madrid: Cátedra, 1990.

PALEOTTI, Gabriele. Discorso intorno alle imagine sacre et profane. Bolonia, 1582.

PALOMINO, Antonio. Museo Pictórico y Escala Óptica. Madrid, 1715-1724. Reed. CEÁN Y BERMÚDEZ, J. A. Madrid: Aguilar, 1947.

PÉREZ SÁNCHEZ, Alfonso Emilio. El dibujo español de los siglos de oro. Madrid: Ministerio de Cultura, 1980.

PÉREZ SÁNCHEZ, Alfonso Emilio. "Vicente Salvador Gómez: A propósito de una obra adquirida para el Prado". Boletín del Museo del Prado, 1, 1980, pp. 69-78. 
PÉREZ SÁNCHEZ, Alfonso Emilio. Historia del dibujo en España de la Edad Media a Goya. Madrid: Cátedra, 1986.

PINAULT, Madeleine. "L'expression des passions à travers quelques exemples de dessins du XVIle siècle". La Peinture des Passions de la Renaissance à l'âge classique. Saint-Étienne: Université de Saint-Étienne, 1995, pp. 317-319.

PONZ, Antonio. Viaje de España, en que se da noticia de las cosas más apreciables y dignas de saberse que hay en ella. Madrid, 1789. Reed. Madrid: Aguilar, 1947.

PRODI, Paolo. "Richerche sulla teorica delle arti figurative nella reforma católica". Archivio Italiano per la storia della pietà, 4, 1962, pp. 123-212.

PSEUDO-ARISTÓTELES. Fisiognomía (ed.). MARTíNEZ MANZANO T. y CALVO DELCÁN, C. Madrid: Gredos, 1999.

RICCI, Fray Juan. Tratado de la pintura sabia. Madrid, C. 1650. Reed. TORMO, E. Madrid: Ministerio de Instrucción Pública y Bellas Artes, 1930.

RODRÍGUEZ MOÑINO, Antonio, "Introducción". En: GARCÍA HIDALGO, J. Principios para estudiar el nobilísimo y real arte de la pintura. Madrid, 1691. Reed. Madrid: Instituto de España, 1965.

ROSAND, David. "Rubens's Munich Lion Hunt: Its Sources and Significance". The Art Bulletin, Vol. 51, No. 1. (Mar. 1969), pp. 29-40.

RUBIN, Laurie et al. Children of Mercury. The Education of Artist in the Sixteenth and Seventeenth Centuries. Providence, Rhode lland: Dept. de Art, Brown University, 1984.

RUIZ ORTEGA, Manuel. La escuela gratuita de diseño de Barcelona, 1774-1808. Barcelona: Biblioteca de Catalunya, 1999.

SALORT PONS, Salvador; LÓPEZ AZORÍN, María José y NAVARRETE PRIETO, Benito. "Vicente Salvador Gómez, Alonso Cano y la pintura valenciana de la segunda mitad del siglo XVII". Archivo Español de Arte, 74, n² 296, 2001, pp. 393-424.

SALVADOR GÓMEZ, Vicente. Cartilla y fundamentales reglas de pintura. Valencia: 1674 (BPR II/3727).
SÁNCHEZ CANTÓN, Francisco Javier. "La librería de Velázquez". En: Homenaje a Menéndez Pidal. Madrid: Hernando, 1925, Vol. 3, pp. 379-406.

SÁNCHEZ CANTÓN, Francisco Javier. Dibujos españoles: material reunido por el Centro de estudios históricos. 5 vols. Madrid: Hauser y Menet, 1930.

SÁNCHEZ CANTÓN, Francisco Javier. Fuentes literarias para la Historia del Arte Español. Madrid: Bermejo impresor, 1934.

SÁNCHEZ CANTÓN, Francisco Javier (1). "Los libros españoles que poseyó Velázquez". En: Varia Velazqueña. Madrid: CSIC, 1960, Vol. 1, pp. 640-648.

SÁNCHEZ CANTÓN, Francisco Javier (2). "Biblioteca de Velázquez". En: Varia Velazqueña. Madrid: CSIC, 1960, Vol. 2, pp. 391-400.

SARRÍA, G. "El doctor Gerónimo Cortés". Cuadernos de historia, $\mathrm{n}^{\circ}$ 7, 1997, pp. 215-248.

THORNDIKE, Lynn. A history of magic and experimental science. Nueva York: Columbia University Press, 1923.

THORNDIKE, Lynn. Michael Scott. Londres: Nelson, 1965.

TORRINI, Maurizio et al. Giovanni Battista della Porta nell'Europa del suo tempo: atti del convegno Giovan Battista della Porta. Nápoles: Guida editori, 1990.

VASARI, Giorgio. Le vite de' più eccellenti pittori scultori e architettori. Florencia, 1568.

VEGA, Jesusa. "Los inicios del Artista. El dibujo base de las artes". En: La formación del artista. Madrid: Real Academia de BBAA de San Fernando, 1989.

VEGA, Jesusa, et al. La formación del artista. De Leonardo a Picasso, de Leonardo a Picasso: aproximación al estudio de la enseñanza y el aprendizaje de las Bellas Artes. Madrid: Real Academia de BBAA de San Fernando, 1989.

WETHEY, Harold. "El testamento de Alonso Cano". Boletín de la Sociedad Española de Excursiones, LVII, 1953, pp. 117-127.

ZERI, Federico. Pittura e controriforma. Turín: Einaudi, 1957. 
